OPEN ACCESS

$$
\begin{array}{r}
\text { Edited by: } \\
\text { Iris Meier, } \\
\text { United States } \\
\text { Reviewed by: } \\
\text { Michael Rout, } \\
\text { The Ohio State University, } \\
\text { United States } \\
\text { Anindya Ganguly, } \\
\text { The Rockefeller University, } \\
\text { University of Virginia, United States } \\
\text { *Correspondence: } \\
\text { Marcel Wiermer } \\
\text { wiermer@uni-goettingen.de } \\
\text { tPresent address: } \\
\text { Daniel Lüdke, } \\
\text { The Sainsbury Laboratory, University } \\
\text { of East Anglia, Norwich, } \\
\text { United Kingdom } \\
\text { fORCID: } \\
\text { Daniel Lüdke }
\end{array}
$$

authorship

Specialty section:

This article was submitted to

Plant Cell Biology,

a section of the journal

Frontiers in Plant Science

Received: 02 June 2021

Accepted: 09 July 2021

Published: 28 July 2021

Citation:

Lüdke D, Rohmann PFW and Wiermer M (2021) Nucleocytoplasmic

Communication in Healthy

and Diseased Plant Tissues.

Front. Plant Sci. 12:719453.

doi: 10.3389/fpls.2021.719453

\section{Nucleocytoplasmic Communication in Healthy and Diseased Plant Tissues}

\author{
Daniel Lüdke ${ }^{1 \dagger \neq \S}$, Philipp F. W. Rohmann ${ }^{1 \neq \S}$ and Marcel Wiermer ${ }^{1,2 * \neq}$ \\ 'Molecular Biology of Plant-Microbe Interactions Research Group, Albrecht-von-Haller-Institute for Plant Sciences, \\ University of Göttingen, Göttingen, Germany, ${ }^{2}$ Molecular Biology of Plant-Microbe Interactions Research Group, Göttingen \\ Center for Molecular Biosciences, University of Göttingen, Göttingen, Germany
}

The double membrane of the nuclear envelope (NE) constitutes a selective compartment barrier that separates nuclear from cytoplasmic processes. Plant viability and responses to a changing environment depend on the spatial communication between both compartments. This communication is based on the bidirectional exchange of proteins and RNAs and is regulated by a sophisticated transport machinery. Macromolecular traffic across the NE depends on nuclear transport receptors (NTRs) that mediate nuclear import (i.e. importins) or export (i.e. exportins), as well as on nuclear pore complexes (NPCs) that are composed of nucleoporin proteins (NUPs) and span the NE. In this review, we provide an overview of plant NPC- and NTR-directed cargo transport and we consider transport independent functions of NPCs and NE-associated proteins in regulating plant developmental processes and responses to environmental stresses.

Keywords: nuclear pore complex (NPC), nucleoporins (NUPs), nuclear transport receptors (NTRs), nucleocytoplasmic transport, plant development and immunity

\section{NUCLEAR PORE COMPLEXES - SELECTIVE TRANSPORT HUBS FOR MACROMOLECULAR EXCHANGE BETWEEN THE CYTOPLASM AND THE NUCLEUS}

The nuclear envelope (NE) is a key compartment border of eukaryotic cells, partitioning cytoplasmic and nuclear processes. It consists of an outer nuclear membrane (ONM) and an inner nuclear membrane (INM). These two lipid bilayers enclose an intermembrane lumen that is termed the perinuclear space and is continuous with the lumen of the endoplasmic reticulum (ER). The partitioning of essential cellular processes by the NE, such as nuclear transcription of genetic information and the cytoplasmic translation of transcripts into proteins by ribosomes, requires the regulated exchange of molecular information between both compartments. The primary pathways for the bidirectional communication across the NE are nuclear pore complexes (NPCs). NPCs are supramolecular protein conglomerates that consist of multiple copies of approximately 30 nucleoporins (NUPs) and fuse the ONM and INM to form a central transport channel across the NE (Tamura and Hara-Nishimura, 2013; Schwartz, 2016; Tang et al., 2020). Nucleoporins containing intrinsically disordered phenylalanine (F)-glycine $(\mathrm{G})$ repeat domains form a selective permeability barrier within the central channel. This barrier prevents the passive diffusion of soluble molecules $>\sim 40 \mathrm{kDa}$ but also enables the energy-dependent selective translocation of nuclear transport receptors (NTRs) that bind localization motifs of macromolecular cargos 
(Christie et al., 2016; Raveh et al., 2016; Schmidt and Görlich, 2016). The small GTPase RAS-RELATED NUCLEAR PROTEIN (RAN) in its GTP-bound nuclear and GDP-bound cytoplasmic states both energizes and determines the directionality of nucleocytoplasmic transport mediated by NTRs of the karyopherin family (Nielsen, 2020). Inside the nucleoplasm, Ran-GTP dissociates imported cargos from nuclear import receptors (termed importins), but stabilizes the association of export receptors (termed exportins) with their nuclear cargo substrates. After translocation into the cytoplasm, exportin/cargo complexes dissociate due to the hydrolysis of Ran.GTP to Ran.GDP by RAN GTPase-ACTIVATING PROTEIN (RanGAP) and its co-factor RAN BINDING PROTEIN (RanBP; Nielsen, 2020).

Macromolecules that are transported in a Ran.GTP/GDP gradient-dependent manner via NTRs of the karyopherin family include proteins as well as different RNA species that are generated inside the nucleus, such as transfer-RNAs (tRNAs) and diverse regulatory small RNAs and ribosomal RNAs (rRNAs; Köhler and Hurt, 2007). By contrast, the export of messenger RNAs (mRNAs) operates independently of the RAN cycle and involves a conserved export receptor heterodimer (termed Mex67-Mtr2 in yeast and TAP-p15 in metazoans) that is structurally unrelated to karyopherins. This general mRNA export receptor operates together with RNA-binding proteins (RBPs) and processing factors that are recruited to the mRNA during messenger ribonucleoprotein particle (mRNP) biogenesis and nuclear export (Segref et al., 1997; Grüter et al., 1998; Sträßer et al., 2002; Masuda et al., 2005; Katahira, 2012; Ehrnsberger et al., 2019). The unidirectionality of mRNA transport through the NPC is imposed by an mRNP remodeling machinery on the cytoplasmic side of the NPC that frees the mRNA for ribosomal translation in the cytoplasm (Snay-Hodge et al., 1998; Tseng et al., 1998; Stewart, 2010; Ehrnsberger et al., 2019). It should be noted, that our current understanding of nuclear transport principles and the NPC structure is largely derived from work in yeast and vertebrates, and divergence from the described transport mechanisms may exist in different eukaryotes, including plants. This also includes trypanosomes that appear to employ a RANdependent system for mRNA export similar to protein transport (Obado et al., 2016).

Besides their fundamental functions in controlling the selective bidirectional exchange of macromolecules between the nucleoplasm and the cytoplasm, NPCs also play transport independent roles in several other cellular processes, including the spatial chromatin organization and gene positioning at the nuclear periphery to regulate gene expression in response to developmental and environmental stimuli (Meier et al., 2017; Groves et al., 2020).

\section{NPC AND NTR FUNCTIONS IN PLANT DEVELOPMENT AND ENVIRONMENTAL RESPONSES}

Plants have to integrate information on a multitude of abiotic and biotic environmental stimuli with endogenous developmental programs to ensure proper growth and reproduction. Adaptations to these stimuli requires the dynamic signal transmission across the NE to drive changes in gene expression upon response pathway activation by cell surface or intracellular receptors. Consistent with nucleoporins being the building blocks of the multifunctional NPC, and NTRs mediating cargo translocation across the NPC, several nucleoporins and NTRs have been shown to participate in different molecular processes during plant adaptations to developmental and environmental cues.

\section{NTR Functions in Plant Development and Stress Signaling}

Canonical protein transport routes into the nucleus depend on NTRs of the importin- $\alpha$ (IMP- $\alpha$ ) and importin- $\beta$ family (IMP- $\beta$; Christie et al., 2016). $\alpha$-importins act as adaptors that recognize and bind to nuclear localization signals (NLSs) of cargo proteins. Subsequently, association of the cargo-NLS/importin$\alpha$ complex with importin- $\beta$ receptors enables translocation of the ternary complex through the FG-NUP permeability barrier of the NPC (Figure 1). However, importin- $\beta$ receptors can recognize and import cargo proteins independently of importin$\alpha$ adaptors (Figure 1; Christie et al., 2016). In addition, some karyopherin family members also bind to nuclear export signals (NESs) to facilitate the nuclear export of proteins and small RNAs, and are therefore termed exportins (Figure 1; Kutay and Güttinger, 2005).

In higher eukaryotes, there is a considerable expansion of the importin- $\alpha$ gene family (Pumroy and Cingolani, 2015). The genome of the model plant Arabidopsis thaliana for example encodes for nine $\alpha$-importins, whereas yeast only encodes a single importin- $\alpha$ (Yano et al., 1992; Wirthmueller et al., 2013, 2015). This expansion might reflect adaptations toward more complex tissue- and/or stimulus-specific nuclear import mechanisms during developmental processes of higher eukaryotes and in response to environmental cues (Wirthmueller et al., 2013, 2015; Pumroy and Cingolani, 2015). Alternatively, a largely redundant repertoire of import adaptors could present a strategy to effectively buffer and protect vital signaling pathways. Indeed, the loss of a single importin- $\alpha$ gene has no obvious morphological consequences in Arabidopsis, while higher order mutants of $I M P-\alpha 1 / 2 / 3$ display a stunted growth morphology (Chen et al., 2020; Lüdke et al., 2021). Chen et al. (2020) also reported that triple mutant plants of $I M P-\alpha 1 / 2 / 3$ flower early and accordingly, the authors identified the three $\alpha$-importins as adaptors that import LIKE HETEROCHROMATIN PROTEIN1 (LHP1; Table 1). LHP1 acts as a transcriptional repressor of flowering-related genes and is involved in the epigenetic regulation of developmental processes, providing an explanation for the observed flowering phenotype of the triple mutant plants (Chen et al., 2020).

Besides its partially redundant role with IMP- $\alpha 1$ and $-\alpha 2$ in plant development, a selective role of $I M P-\alpha 3$ has been described in immunity (Lüdke et al., 2021). Based on the genetic requirement for the autoimmune phenotype of suppressor of npr1-1, constitutive1 (snc1), a gain-of-function mutant 


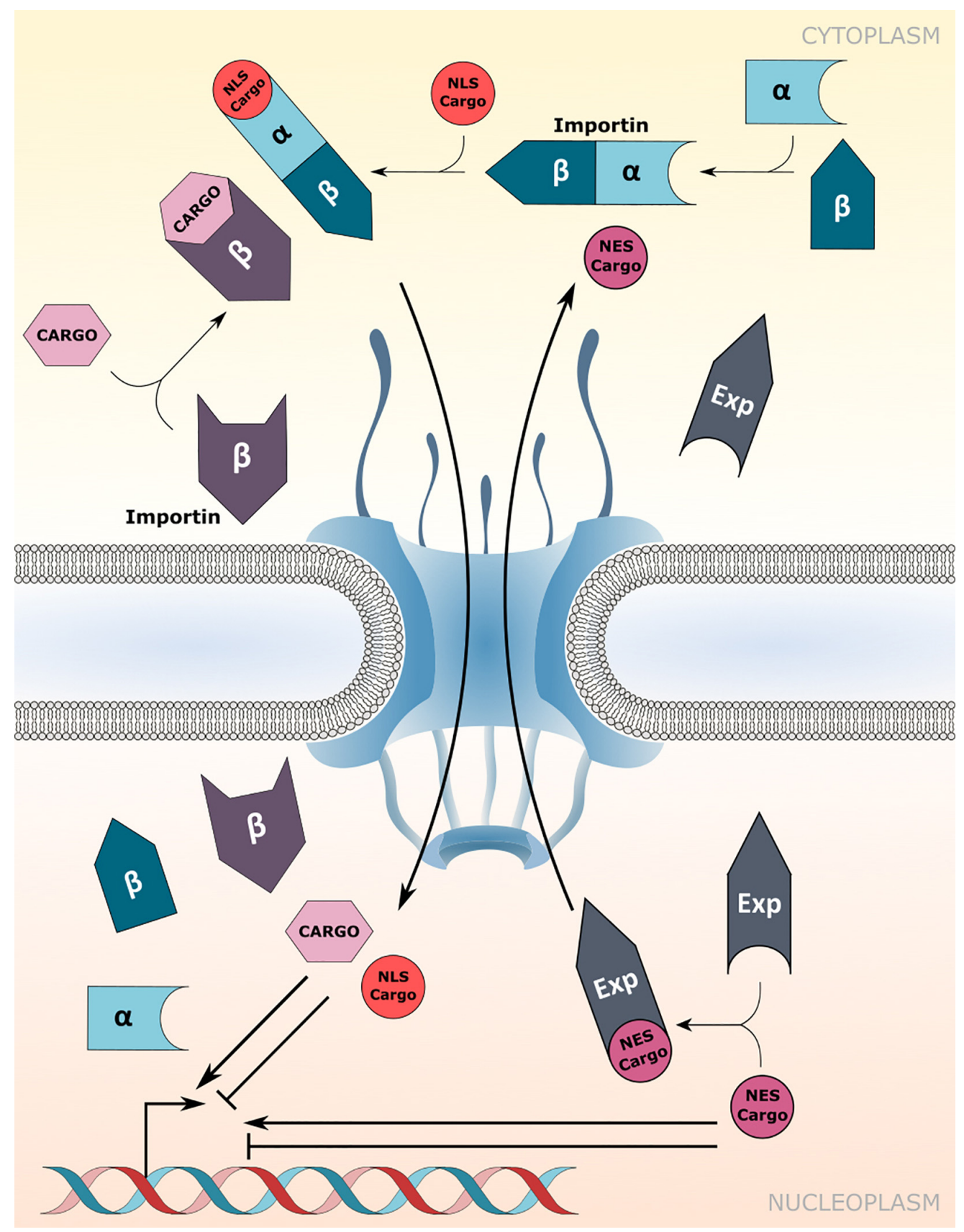

FIGURE 1 | Nuclear transport receptor-mediated nucleocytoplasmic transport. Nuclear import of nuclear localization signal (NLS) containing cargo proteins via importin- $\alpha / \beta$ heterodimers or direct cargo-association with importin- $\beta$ receptors. Nuclear export is mediated by association of exportins (Exp) with the nuclear export signal (NES) of cargo proteins. Transport directionality is indicated by curved arrows. Imported cargos or cargo destined for export may directly influence/drive transcriptional changes inside the nucleus. Experimentally verified cargos of importins and exportins are listed in Table 1.

of a nucleotide-binding leucine-rich repeat (NLR) immune receptor, IMP- $\alpha 3$ was named MODIFIER OF SNC1, 6 (MOS6; Palma et al., 2005). NLRs usually detect the presence or actions of immune suppressive pathogen effector molecules, but a nuclear function of SNC1 in the transcriptional regulation of defense genes and miRNAs has also been described (Zhu et al., 2010; $\mathrm{Xu}$ et al., 2014; Cai et al., 2018). Recent work suggests that
MOS6 is the main import adapter for SNC1 (Table 1; Lüdke et al., 2021). This is consistent with the finding that the loss of MOS6, but not of any other $\alpha$-importin, partially suppresses the autoimmune phenotype of $s n c 1$ (Palma et al., 2005; Lüdke et al., 2021). In addition, the genetic requirement of MOS6 but not of other $\alpha$-importins for basal resistance, together with the finding that MOS6 but not its closest homolog IMP- $\alpha 6$ interacts 
TABLE 1 | Nuclear transport receptors and their cargos.

\begin{tabular}{|c|c|c|c|}
\hline $\begin{array}{l}\text { Nuclear transport } \\
\text { receptor }\end{array}$ & AGI code & Cargo(s) & References \\
\hline $\mid M P-\alpha 1$ & AT3G06720 & LHP1 & Chen et al., 2020 \\
\hline IMP- $\alpha 2$ & AT4G16143 & LHP1, PARP2 & Chen et al., 2018, 2020 \\
\hline IMP- $\alpha 3 / \operatorname{MOS} 6$ & AT4G02150 & $\begin{array}{l}\text { LHP1, TN13, } \\
\text { SNC1, BDL }\end{array}$ & $\begin{array}{l}\text { Herud et al., 2016; } \\
\text { Roth et al., 2017; Chen } \\
\text { et al., 2020; Lüdke } \\
\text { et al., } 2021\end{array}$ \\
\hline IMP- $\alpha 4$ & AT1G09270 & IYO, PARP2 & $\begin{array}{l}\text { Muñoz et al., 2017; } \\
\text { Chen et al., 2018; } \\
\text { Contreras et al., } 2019\end{array}$ \\
\hline IMP- $\alpha 6$ & AT1G02690 & BDL, PIP5K2 & $\begin{array}{l}\text { Herud et al., 2016; } \\
\text { Gerth et al., } 2017\end{array}$ \\
\hline KETCH1 & AT5G19820 & HYL1 & Zhang et al., 2017 \\
\hline IMP- $\beta 4$ & AT4G27640 & GIF1-3, JANUS & $\begin{array}{l}\text { Liu et al., 2019; Xiong } \\
\text { et al., } 2020\end{array}$ \\
\hline SAD2 & AT2G31660 & MYB4 & $\begin{array}{l}\text { Zhao et al., 2007; } \\
\text { Panda et al., } 2020\end{array}$ \\
\hline TRN-SR/MOS14 & AT5G62600 & SR proteins & Xu et al., 2011 \\
\hline XP01A & AT5G17020 & XIW1, HDA6 & $\begin{array}{l}\text { Xu et al., 2019; Zhu } \\
\text { et al., } 2019\end{array}$ \\
\hline XPO1B & AT3G03110 & XIW1 & Xu et al., 2019 \\
\hline PSD/XPOT & AT1G72560 & tRNAs & $\begin{array}{l}\text { Hunter et al., 2003; } \\
\text { Park et al., } 2005\end{array}$ \\
\hline XPO4 & AT3G04490 & TPL, TPRs & Xu et al., 2021 \\
\hline
\end{tabular}

with the truncated NLR TIR-NB13 (TN13), further suggests a specialization of MOS6/IMP- $\alpha 3$ in immunity-related cargo transport (Roth et al., 2017). In contrast, a pronounced function of IMP- $\alpha 6$ that partially overlaps with the function of IMP- $\alpha 3$ has been described for the nuclear uptake of the Aux/IAA protein BODENLOS (BDL) during primary root meristem formation (Table 1; Herud et al., 2016).

There are further examples of importin- $\alpha$ cargo selectivity but also of redundancy in plants (Jiang et al., 2001; Kanneganti et al., 2007; Bai et al., 2008; Gerth et al., 2017). For instance, cargo selectivity has been described for MINIYO (IYO), which interacts with IMP- $\alpha 4$, but not with IMP- $\alpha 3$ or IMP- $\alpha 6$ in transient assays and mass spectrometry analysis (Table 1; Muñoz et al., 2017; Contreras et al., 2019). MINIYO plays a vital role in stem cell differentiation, but no morphological phenotype has been described for imp- $\alpha 4$ mutant plants, suggesting additional import routes for MINIYO (Helizon et al., 2018; Lüdke et al., 2021). On the other hand, loss of IMP- $\alpha 4$ but not of other $\alpha$-importins affects transformation of Arabidopsis roots by the plant pathogen Agrobacterium tumefaciens, although IMP- $\alpha 4$ and several other importin- $\alpha$ transport adapters are capable to interact with Agrobacterium effector proteins that mediate nuclear import of the T-DNA/protein complex (T-complex; Bhattacharjee et al., 2008). IMP- $\alpha 4$ shows the highest expression level in roots among the Arabidopsis importin- $\alpha$ isoforms (Wirthmueller et al., 2013), indicating that IMP- $\alpha 4$ is the most relevant NTR for import of the T-complex and thus is exploited by Agrobacterium to promote plant transformation and disease progression. Importin- $\alpha$ mediated transport redundancy has been demonstrated for FARRED (FR) ELONGATED HYPOCOTYL1 (FHY1) that acts as an NLS-containing facilitator in nuclear translocation of FR light-activated phytochrome A (phyA) termed Pfr (Helizon et al., 2018). In another example, the POLY(ADP-RIBOSE) POLYMERASE2 (PARP2), that contributes to DNA-damage repair and responses to abiotic and biotic stresses, associates with multiple importin- $\alpha$ isoforms, but shows preferential binding to IMP- $\alpha 2$ and IMP- $\alpha 4$ (Table 1; Chen et al., 2018). The molecular basis that determines functional specialization vs. redundancy of $\alpha$-importins within the divers nuclear protein import pathways remain to be experimentally dissected in plants. However, it seems plausible that in plants nuclear import kinetics and cargo recognition specificities are regulated at several layers, including different preferences for association of $\alpha$ - with $\beta$-importins, as well as stimulus-dependent post-translational modifications of both the NLS-cargo and the NTR(s) to either enhance or prevent importin- $\alpha$ /cargo interactions (Christie et al., 2016).

In contrast to defects in importin- $\alpha$ transport adapters, mutations in other karyopherin family member genes often result in pleiotropic phenotypes. This might also reflect that several $\alpha$-importins redundantly depend on a specific $\beta$-importin for nuclear import of a broad cargo range. Indeed, a loss of KARYOPHERIN ENABLING THE TRANSPORT OF THE CYTOPLASMIC HYL1 (KETCH1) is embryo lethal (Meinke et al., 2008). The primary miRNA processing factor HYPONASTIC LEAVES1 (HYL1), and several ribosomal proteins have been elucidated as KETCH1 imported cargos (Table 1; Zhang et al., 2017). A role in developmental processes has recently also been described for IMP- $\beta 4$ which imports transcriptional regulators of PLETHORA, thereby regulating meristem and ovule development (Liu et al., 2019; Xiong et al., 2020). IMP- $\beta 4$ also interacts with the kinesin FRAGILE FIBER1 (FRA1) to protect it from proteasomal degradation and to inhibit the motility of FRA1 by preventing its binding to microtubules. Importantly, this function of IMP- $\beta 4$ appears to operate independently of its transport activity, as the binding of IMP- $\beta 4$ does not lead to translocation of FRA1 into the nucleus (Ganguly et al., 2018). In Arabidopsis, KPNB1/IMP- $\beta 1$ is involved in ABA-mediated drought stress responses, yet cargos imported by KPNB1, either directly or via its association with multiple $\alpha$-importins, are still elusive as for most other NTRs (Luo et al., 2013; Oh et al., 2020). Pleiotropic developmental defects such as ABA-hypersensitivity and reduced trichome numbers have been reported for super sensitive to $A B A$ and drought2 (sad2) mutants (Verslues et al., 2006; Gao et al., 2008; Yoshida et al., 2009). SAD2 also mediates nuclear import of MYB4, a transcriptional repressor of the phenylpropanoid metabolism that regulates lignin biosynthesis (Zhao et al., 2007; Panda et al., 2020). In addition, SAD2 acts as a negative regulator of miRNA pathways and functions in $\mathrm{Ca}^{2+}$ - and reactive oxygen species (ROS)-mediated cell death responses, arguing for its involvement in several signaling pathways and physiological responses (Wang et al., 2011; Zheng et al., 2020). The discovery of an additional MOS gene, MOS14, that encodes for the importin- $\beta$ superfamily protein TRANSPORTIN (TRN)-SR, further outlines the importance of the nucleocytoplasmic trafficking machinery for plant immune responses. The loss of MOS14 influences the splicing patterns of $N L R$ transcripts, including $S N C 1$, due 
to reduced nuclear accumulation of serine-arginine rich (SR) proteins, which are required for splice site recognition and spliceosome assembly (Xu et al., 2011).

The involvement in several signaling pathways has also been described for EXPORTIN1 (XPO1). Xpo1a mutant plants show an impaired heat-stress response, while xpo1a xpo1b double mutant plants are lethal due to defects in gametogenesis (Blanvillain et al., 2008; Wu et al., 2010). XPO1A and XPO1B are further required in the $\mathrm{ABA}$ response pathway and were shown to be export factors for a positive regulator of the ABA-response, named XPO1-Interacting WD40 protein1 (XIW1; Table 1; Xu et al., 2019). In addition, HISTONE DEACETYLASE6 (HDA6), a transcriptional gene silencing factor, interacts with XPO1A and accumulates in nuclei of xpola mutant plants, further demonstrating the pleiotropic role of XPO1A in nuclear export (Table 1; Zhu et al., 2019). Mutants of the Arabidopsis exportins PAUSED (PSD)/EXPORTIN-T and HASTY (HST)/EXPORTIN5 display a delay or acceleration in a range of developmental processes, respectively (Bollman et al., 2003; Hunter et al., 2003; Li and Chen, 2003). While PSD exports tRNAs, hst mutants show reduced miRNA levels without affecting the subcellular distribution of miRNAs (Park et al., 2005; Bologna et al., 2018; Cambiagno et al., 2020). Since HST interacts with proteins of the mediator (MED) complex that is part of the transcriptional machinery, HST might have a function as an export-independent scaffold for transcription and processing of primary miRNA transcripts (Cambiagno et al., 2020).

Overall, the number of elucidated NTR cargos and interaction partners remains limited. This might be explained by the transient nature of the interaction between NTRs and their cargo clients. Xu et al. (2021) recently demonstrated that the use of proximity-based labeling approaches provides exciting new possibilities for the identification of cargo-NTR associations in plants. Using TurboID-tagged variants of several exportins, the authors provide evidence for a selective interaction of EXPORTIN4 (XPO4) with members of the TOPLESS (TPL) and TPL-related (TPR) protein family (Table 1). Consistent with the observation that the loss of XPO4 function enhances autoimmunity of the nucleoporin mutant cpr5 (constitutive expresser of $P R$ genes5), the authors show that the export activity of XPO4 counteracts nuclear accumulation of TPL and TPRs, which are involved in transcriptional co-repression of negative regulators of immunity (Zhu et al., 2010; Xu et al., 2021). The modulation of distinct signaling pathways observed in cpr5 and other nucleoporin mutants outlines the importance and active contribution of NPC components in the regulation of nuclear translocation processes.

\section{Nucleoporin Functions in Protein Transport and Homeostasis}

CRP5 is a plant-specific transmembrane nucleoporin which forms homomeric complexes and associates with the core scaffold of the NPC in steady-state tissues (Gu et al., 2016). Upon activation of effector-triggered immunity (ETI) by intracellular NLR immune receptors, CPR5 undergoes a conformational switch that disrupts CPR5 oligomer formation and hence the selective barrier of the NPC. This is considered to allow massive nuclear import of ETI-related signaling cargos, including cyclindependent kinase inhibitors (CKIs) that dissociate from the NPC upon CPR5 monomerization to enable the expression of immune response genes (Figure 2 and Table 2; Wang et al., 2014; Gu et al., 2016). Consistent with a negative regulatory role of CPR5 in ETI by preventing uncontrolled nuclear influx of stress signaling cargos, cpr5 mutant plants show an autoimmune phenotype, whereas overexpression of CRP5 compromises resistance and ETI-associated programmed cell death (PCD; Wang et al., 2014; Gu et al., 2016).

The modulation of plant immune responses at the level of protein translocation across the NPC has also been revealed for Arabidopsis NUP88/MOS7 and significantly, the autoimmune phenotype of cpr5 is suppressed by the partial loss-of-function mutation mos7-1, causing a four amino acid deletion (Cheng et al., 2009; Wiermer et al., 2010; Genenncher et al., 2016; $\mathrm{Gu}$ et al., 2016). NUP88/MOS7 attenuates nuclear export rates of important nucleocytoplasmic defense proteins, such as the regulator of pattern-triggered basal defense and TIR-type NLRmediated immunity ENHANCED DISEASE SUSCEPTIBILITY1 (EDS1), and NONEXPRESSOR OF PATHOGENESIS-RELATED GENES1 (NPR1) that functions as a receptor for the plant defense hormone salicylic acid (SA; Figure 2 and Table 2; Mou et al., 2003; Feys et al., 2005; Cheng et al., 2009; García et al., 2010; Genenncher et al., 2016). The genetic dependency of cpr5 autoimmunity on MOS7 implies that a MOS7-mediated nuclear retention of common stress signaling cargos is required for (auto)immunity and PCD upon CPR5 gated nuclear cargo influx. Indeed, Gu et al. (2016) showed that the overexpression of CPR5 constrains the nuclear translocation of NPR1 as well as of other stress- and plant hormone-related nuclear signaling cargos. These examples suggest that nuclear protein influx and efflux are regulated by distinct NPC constituents to mount a robust immune response.

Consistent with the phenotype of nup88 mutations in other organisms, null alleles of Arabidopsis mos7 are lethal, suggesting that in addition to its function in regulating a diverse set of plant immune responses, wild-type MOS7/NUP88 is also essential for regular plant growth and development (Cheng et al., 2009; Wiermer et al., 2010). Accordingly, work by Park et al. (2014) implicates MOS7/NUP88 in mitosis during female and male gametophyte formation and seed development. Using forward genetics, the authors identified mos7-5, which results in ovule and pollen abortion in heterozygous mos75/MOS7 plants. Whereas MOS7 localizes to the NE during interphase, it associates with mitotic microtubules during cell division, suggesting additional transport-independent functions of MOS7 in microtubule organization and dynamics (Park et al., 2014). NUP88/MOS7 interacts with the FG-NUPs NUP98A and NUP98B which appears to be essential to regulate the permeability of the NPC for certain immune regulatory cargo proteins (Figure 2; Cheng et al., 2009; Genenncher et al., 2016). Indeed, nup98a mutant plants are more susceptible to Botrytis cinerea infection (Genenncher et al., 2016). Consistent with immune-regulatory roles of NUP98 in Arabidopsis, its putative homolog in rice, APIP12, is required for resistance to the rice 


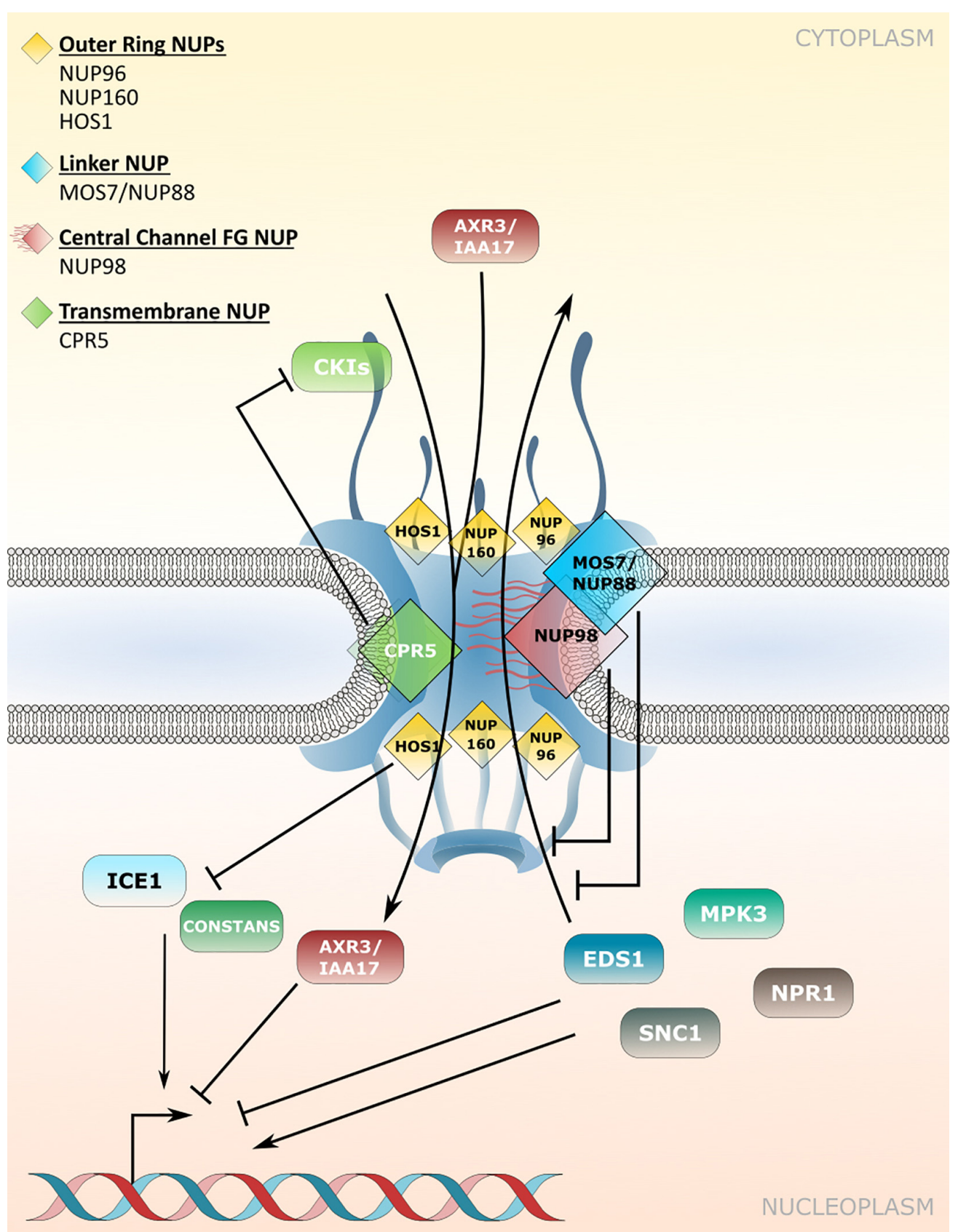

FIGURE 2 | Nucleoporin and NPC-associated protein functions in nucleocytoplasmic protein transport. Several nucleoporins regulate protein transport through the NPC. CPR5 controls influx of cyclin-dependent kinase inhibitors (CKIs) during effector-triggered immunity (ETI), while MOS7/NUP88 associates with the FG-repeat containing NUP98 to attenuate nuclear efflux of several immunity related proteins. The NUP107-160 complex members NUP96 and NUP160 associate with HOS1 and regulate the nuclear protein abundance of temperature and flowering associated factors. Several NUP regulated cargos influence transcriptional responses in the nucleus. Table 2 lists nucleoporin functions in protein transport and the respective nucleoporin mutant phenotypes.

blast fungus Magnaporthe oryzae and is targeted by the M. oryzae effector AvrPiz-t (Tang et al., 2017).

In Arabidopsis, additional roles of NUP98 in plant environmental responses and development have been revealed. For example, NUP98A was identified in a genetic screen for regulatory components of the shade avoidance syndrome (SAS) and has been termed DRACULA2 (DRA2; Table 2;
Gallemí et al., 2016). NUP98A/DRA2 appears to be a dynamic nucleoporin, as it localizes to the nuclear rim as well as to the cytoplasm and the nucleoplasm when transiently overexpressed (Gallemí et al., 2016). It is currently unknown whether the SAS phenotype of dra2 mutant plants is caused by light-dependent alterations in the nucleocytoplasmic translocation of light signal transducers such as phytochrome photoreceptors, and/or based 
TABLE 2 | Nucleoporin and NPC-associated protein functions in nucleocytoplasmic protein transport.

\begin{tabular}{|c|c|c|c|}
\hline Nucleoporin & AGI code & $\begin{array}{l}\text { Cellular functions } \\
\text { (mutant phenotypes) }\end{array}$ & References \\
\hline CPR5 & AT5G64930 & $\begin{array}{l}\text { ETI-triggered } \\
\text { CPR5-monomerization } \\
\text { enables nuclear influx } \\
\text { of CKIs; (cpr5: } \\
\text { autoimmunity) }\end{array}$ & $\begin{array}{l}\text { Wang et al., } \\
\text { 2014; Gu et al., } \\
2016\end{array}$ \\
\hline NUP88/MOS7 & AT5G05680 & $\begin{array}{l}\text { Attenuates nuclear } \\
\text { export rates of EDS1, } \\
\text { SNC1, NPR1, MPK3; } \\
\text { (mos7-1: increased } \\
\text { susceptibility to diverse } \\
\text { pathogens; het. } \\
\text { mos7-5: ovule and } \\
\text { pollen abortion; lethality } \\
\text { of mos7 null alleles) }\end{array}$ & $\begin{array}{l}\text { Cheng et al., } \\
\text { 2009; Park } \\
\text { et al., 2014; } \\
\text { Genenncher } \\
\text { et al., } 2016\end{array}$ \\
\hline NUP98A/DRA2 & AT1G10390 & $\begin{array}{l}\text { Interacts with MOS7 to } \\
\text { regulate plant immunity; } \\
\text { involved in SAS } \\
\text { regulation; positive } \\
\text { regulator of starch } \\
\text { degradation; (nup98a: } \\
\text { increased susceptibility } \\
\text { to } B \text {. cinerea, nup98a1 } \\
\text { nup98b1: early } \\
\text { flowering, early } \\
\text { senescence) }\end{array}$ & $\begin{array}{l}\text { Gallemí et al., } \\
\text { 2016; } \\
\text { Genenncher } \\
\text { et al., 2016; } \\
\text { Jiang et al., } \\
\text { 2020; Xiao } \\
\text { et al., } 2020\end{array}$ \\
\hline NUP98B & AT1G59660 & $\begin{array}{l}\text { Interacts with MOS7; } \\
\text { positive regulator of } \\
\text { starch degradation; } \\
\text { (nup98a1 nup98b1: } \\
\text { early flowering, early } \\
\text { senescence) }\end{array}$ & $\begin{array}{l}\text { Genenncher } \\
\text { et al., 2016; } \\
\text { Jiang et al., } \\
\text { 2020; Xiao } \\
\text { et al., } 2020\end{array}$ \\
\hline HOS1 & AT2G39810 & $\begin{array}{l}\text { Mediates degradation } \\
\text { of CONSTANS and } \\
\text { ICE1; (hos 1: early } \\
\text { flowering, enhanced } \\
\text { cold stress tolerance, } \\
\text { nuclear accumulation of } \\
\text { PIF4 at elevated } \\
\text { temperature) }\end{array}$ & $\begin{array}{l}\text { Dong et al., } \\
\text { 2006a; Cheng } \\
\text { et al., 2020; Li } \\
\text { et al., 2020; } \\
\text { Zhang A. et al., } \\
2020\end{array}$ \\
\hline NUP160/SAR1 & AT1G33410 & $\begin{array}{l}\text { Stabilization of HOS1 at } \\
\text { NPC; (nup160: early } \\
\text { flowering, reduced cold } \\
\text { stress tolerance, } \\
\text { reduced nuclear } \\
\text { accumulation of } \\
\text { AXR3/IAA17) }\end{array}$ & $\begin{array}{l}\text { Dong et al., } \\
\text { 2006b; Parry } \\
\text { et al., 2006; } \\
\text { Wiermer et al., } \\
\text { 2012; Li et al., } \\
2020\end{array}$ \\
\hline $\begin{array}{l}\text { NUP96/MOS3/ } \\
\text { SAR3 }\end{array}$ & AT1G80680 & $\begin{array}{l}\text { Stabilization of HOS1 at } \\
\text { NPC; (nup96: early } \\
\text { flowering, reduced } \\
\text { nuclear accumulation of } \\
\text { AXR3/IAA17, nuclear } \\
\text { accumulation of PIF4 at } \\
\text { elevated temperature) }\end{array}$ & $\begin{array}{l}\text { Parry et al., } \\
\text { 2006; Cheng } \\
\text { et al., 2020; } \\
\text { Zhang A. et al., } \\
\text { 2020; }\end{array}$ \\
\hline
\end{tabular}

on its defect in nuclear mRNA export (Gallemí et al., 2016). However, its cellular distribution may provide NUP98A/DRA2 with additional transport-independent functions, such as the regulation of shade-induced gene expression via associations with chromatin or chromatin-bound transcription complexes, as was proposed by Gallemí et al. (2016). Consistent with this idea, metazoan NUP98 is mobile and has multiple reported functions, including the regulation of gene expression via direct associations with chromatin (Griffis et al., 2002; Kalverda et al., 2010). Arabidopsis NUP98A and NUP98B also function redundantly as positive regulators of starch degradation, thus delaying plant senescence (Xiao et al., 2020), and act as negative regulators of flowering in a CONSTANS (CO) transcriptional regulator-independent manner (Jiang et al., 2020).

The early flowering phenotype of nup98a nup98b double mutants is common to several other mutants of nucleoporin encoding genes, including NUP160 and NUP96, two members of the NUP107-160 nuclear pore sub-complex (Table 2; Dong et al., 2006b; Parry et al., 2006; Jacob et al., 2007; Tamura et al., 2010). Whereas this phenotype might be related, at least in part, to defects in nuclear mRNA export (see chapter below), additional defects in protein stability and nuclear protein transport may contribute to the mutant phenotypes. In the case of NUP160 and NUP96, it was reported recently that both nucleoporins associate with and stabilize the E3-ubiquitin ligase HIGH EXPRESSION OF OSMOTICALLY RESPONSIVE GENES1 (HOS1) at the NPC (Figure 2 and Table 2), which negatively regulates flowering transition via ubiquitination and subsequent proteasomal degradation of CO (Cheng et al., 2020; Li et al., 2020). Loss of either HOS1, NUP96 or NUP160 results in nuclear accumulation of $\mathrm{CO}$ and subsequent $\mathrm{CO}$-mediated transcriptional activation of FLOWERING LOCUS T (FT). FT induces the expression of genes that contribute to the formation of floral primordia, providing an explanation for the early flowering phenotypes of hos1, nup96 and nup160 plants (Cheng et al., 2020; Li et al., 2020).

HOS1 also interacts with the transcription factor ICE1 and mediates its degradation in order to attenuate cold responses in Arabidopsis (Figure 2 and Table 2; Dong et al., 2006a). While both, hos 1 and nup160 plants, show an early flowering phenotype, the two mutants show opposite - i.e., enhanced (hos1) and reduced (nup160) - tolerance to cold stress (Dong et al., 2006a,b). Considering that NUP96 and NUP160 promote the stabilization and association of HOS1 at the NPC during flowering regulation (Cheng et al., 2020; Li et al., 2020), a scenario of mutual NUP160-HOS1 stabilization at the NPC appears unlikely in cold stress signaling, and might be attributed to the dynamic nuclear accumulation of HOS1 in response to low temperature (Lee et al., 2001). However, the localization of HOS1 has not been investigated in nup160 or nup96 plants grown under ambient or chilling/freezing conditions. While the nuclear localization of ICE1 is not obviously affected in nup160 plants (Dong et al., 2006b), nup160 (also termed sar1 for suppressor of auxin resistance1) and nup96 (also termed sar3) show reduced nuclear accumulation of the transcriptional repressor AXR3/IAA17 (Figure 2 and Table 2), which may cause the altered auxin-dependent responses of nup160 and nup96 (Parry et al., 2006). This suggests a different extent to which NUP160 and NUP96 modulate the nuclear abundance of protein regulators to coordinate various signaling pathways in response to environmental and developmental cues. This includes adaptations to elevated temperatures mediated by 
the transcription factor PHYTOCHROME INTERACTING FACTOR4 (PIF4; Zhang A. et al., 2020), but could also involve additional functions of these NUP107-160 complex members in nuclear mRNA export.

\section{Nucleoporin Functions in mRNA Transport and Metabolism}

The efficient nuclear export of mature mRNAs via mRNPs to the cytoplasmic translation machinery is a crucial step in cellular responses initiated upon the integration of endogenous and exogenous signals inside the nucleus, which direct transcriptional changes. A central part of mRNP export is the transcriptionexport (TREX) complex, which associates with transcripts and aids in the recruitment of mRNA export adaptors and receptors (Figure 3; Ehrnsberger et al., 2019; Ashkenazy-Titelman et al., 2020). Transport through the permeability barrier of the NPC involves the interaction of mRNPs with the TREX-2 complex that is tethered to the nuclear basket of the NPC (Figure 3). While mRNA adaptors remain inside the nucleus, mRNA export receptors are released upon translocation through the NPC and mRNP remodeling via RNA helicases at the cytosolic side of the NPC (Ehrnsberger et al., 2019; Ashkenazy-Titelman et al., 2020). Components required for mRNP translocation across the NPC are well described in yeast and mammalian systems, but knowledge on mRNP translocation in plants is limited. Although several mRNA export adaptors and TREX complex homologues have been identified in Arabidopsis, prime candidates for plant homologs of the mRNA export receptor are still elusive, suggesting plant-specific export components/mechanisms for this critical step (Ehrnsberger et al., 2019). A loss of mRNA export adaptors, TREX or TREX-2 complex members in Arabidopsis can lead to nuclear mRNA accumulation and affects several developmental and stress response pathways, including plant immunity (Germain et al., 2010; Pan et al., 2012a,b; Sørensen et al., 2017; Uddin et al., 2017; Ehrnsberger et al., 2019). Nuclear mRNA accumulation has also been observed upon mutation of several nucleoporin genes, although the direct molecular functions of most nucleoporins in mRNA export have not been revealed. In addition, the identified nucleoporins can have multiple functions in the translocation of mRNAs and proteins, and may also possess additional transport-independent functions (Ehrnsberger et al., 2019; see chapters on nucleoporins in protein transport, and on transport-independent nucleoporin functions), which could also account for pleiotropic defects observed for some of the nucleoporin mutants.

The nuclear basket localized Arabidopsis nucleoporins NUP136/NUP1 and NUA interact with members of the TREX-2 complex, implicating these components as the first contact site of mRNPs with the plant NPC for translocation (Figure 3; Lu et al., 2010; Yang et al., 2017; Zhang B. et al., 2020). Consistent with this function, a loss of NUP1 and NUA leads to nuclear mRNA accumulation and mutant plants display defects in gametogenesis as well as an early flowering phenotype, while nua mutant plants also show defects in miRNA export (Table 3; Xu et al., 2007; Lu et al., 2010; Tamura et al., 2010; Bao et al., 2019; Zhang B. et al., 2020). Early flowering phenotypes combined with nuclear mRNA accumulation can also be observed in mutant plants with defects in different NUP107-160 complex members such as NUP160 and NUP96, whereas mutants of other complex members like NUP85 or SEH1 do not flower early but also accumulate mRNA inside nuclei (Figure 3 and Table 3; Dong et al., 2006b; Parry et al., 2006; Wiermer et al., 2012; MacGregor et al., 2013; Parry, 2014; Du et al., 2016). This suggests that defects in nuclear mRNA export per se do not cause the mutant plants to flower early. Therefore, certain nucleoporins may be involved in nuclear export of distinct sub-pools of mRNAs, or may possess additional functions that are not related to mRNA transport, thus causing particular mutant phenotypes. Since nucleoporins such as the NUP107-160 complex members associate in larger sub-complexes within the NPC (Tamura et al., 2010; Cheng et al., 2020), it can be speculated whether an overall compromised structural integrity of the NPC is the major reason for bulk mRNA accumulation inside the nucleus of the respective single mutant plants. In such a scenario, the loss of some nucleoporins, like NUP160 or NUP96, may have a stronger impact on the functionality and structural integrity of the NPC compared to mutations in other complex members. This might either be due to multiple interactions with other members of the sub-complex, or because of (partially) redundant functions among the different sub-complex members. In addition, NUP96 protein levels are reduced in hos 1 mutant plants (Cheng et al., 2020), further suggesting that the structural integrity of the NPC is also a prerequisite for the stabilization of other NPC constituents that play a role in mRNA export.

Homologs of yeast/mammalian DEAD-BOX RNA helicases implicated in mRNP remodeling at the cytoplasmic side of the NPC have also been identified in Arabidopsis, which includes LOS4 and GLE1 (Gong et al., 2002; Tamura et al., 2010). Accordingly, both proteins are associated with nucleoporins located on the cytoplasmic side of the NPC (Figure 3). While LOS4 interacts with NUP214, GLE1 has been found in complex with the NPC associated RNA EXPORT FACTOR1 (RAE1; Tamura et al., 2010; Braud et al., 2012). Null mutants of NUP214 and GLE1 are embryo lethal (Braud et al., 2012), while a point mutation in LOS4 leads to mRNA accumulation inside the nucleus and enhanced chilling and freezing stress tolerance, but decreased heat stress tolerance (Gong et al., 2002; Lee et al., 2015). GLE1 also interacts with LOS4 and thereby positively regulates cold stress responses in a phytic acid (insP6) dependent manner, outlining a central role of these nucleoporins in plant responses to temperature changes (Lee et al., 2015).

While most studies report on bulk mRNA accumulation inside nuclei upon mutation of individual nucleoporins, transcript specific export defects have also been revealed. Chen et al. (2019) recently reported that a loss of CPR5 leads to nuclear accumulation of several transcripts encoding for components of the ethylene signaling pathway, whereas nup 96 and nup160 seedling nuclei appear to accumulate a broader or different set of transcripts. In addition, de Leone et al. (2020) disclosed that mutations in EDS4/NUP205, which lead to protein truncation, result in mRNA accumulation, specifically affecting transcripts of circadian clock and immunity related genes (Table 3). Given that several other nucleoporins have 


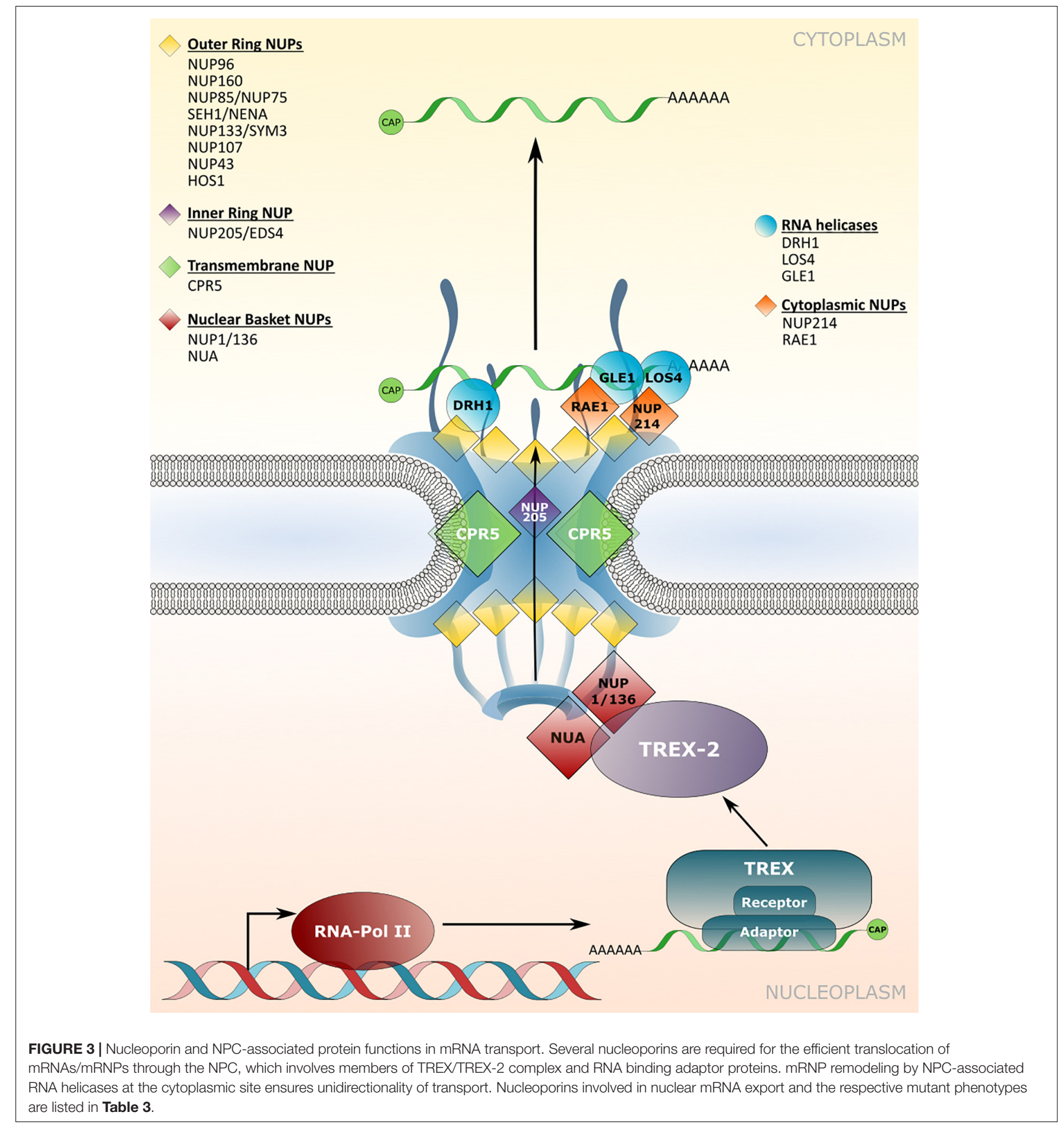

been shown to be required for distinct immune responses, it is tempting to speculate that a subset of mRNAs whose nuclear export is regulated by defense-related nucleoporins encode for proteins implicated in the regulation of particular defense pathways. Although such pathway specificity may also be attributed to additional nucleoporin functions in protein transport or in transport-independent gene-regulatory functions (see chapter below), analyses in other model organisms revealed a preferential association of certain RBPs and export adapters with distinct classes of functionally related mRNAs, indicating that mRNA export pathways are not identical (Hieronymus and Silver, 2003; Kim Guisbert et al., 2005; Köhler and Hurt, 2007). Therefore, distinct nucleoporins may coordinate the nuclear translocation of specific sets of mRNAs by modulating the interaction of mRNPs with the NPC (Moore, 2005; Chakraborty et al., 2008), potentially explaining differences in 
TABLE 3 | Nucleoporin and NPC-associated protein functions in mRNA transport.

\begin{tabular}{|c|c|c|c|}
\hline Nucleoporin & AGI code & $\begin{array}{l}\text { Cellular functions } \\
\text { (mutant phenotypes) }\end{array}$ & References \\
\hline NUP1/136 & AT3G10650 & $\begin{array}{l}\text { Interaction with } \\
\text { THP1/TREX-2 members; } \\
\text { (nup1/136: nuclear } \\
\text { mRNA accumulation, } \\
\text { early flowering, defects in } \\
\text { gametogenesis) }\end{array}$ & $\begin{array}{l}\text { Lu et al., 2010; } \\
\text { Tamura et al., } \\
\text { 2010; Bao et al., } \\
\text { 2019; Zhang B. } \\
\text { et al., } 2020\end{array}$ \\
\hline NUA & AT1G79280 & $\begin{array}{l}\text { Interaction with TREX-2 } \\
\text { member SAC3B; (nua: } \\
\text { nuclear mRNA } \\
\text { accumulation, early } \\
\text { flowering, defects in } \\
\text { miRNA export) }\end{array}$ & $\begin{array}{l}\text { Jacob et al., } \\
\text { 2007; Xu et al., } \\
\text { 2007; Yang et al., } \\
2017\end{array}$ \\
\hline NUP160/SAR1 & AT1G33410 & $\begin{array}{l}\text { Essential for autoimmune } \\
\text { phenotypes of snc1 and } \\
\text { bak1 bkk1; (nup } 160 \text { : } \\
\text { nuclear mRNA } \\
\text { accumulation, early } \\
\text { flowering, increased } \\
\text { susceptibility) }\end{array}$ & $\begin{array}{l}\text { Dong et al., } \\
\text { 2006b; Parry } \\
\text { et al., 2006; } \\
\text { Wiermer et al., } \\
\text { 2012; Du et al., } \\
\text { 2016 }\end{array}$ \\
\hline $\begin{array}{l}\text { NUP96/MOS3/ } \\
\text { SAR3 }\end{array}$ & AT1G80680 & $\begin{array}{l}\text { Essential for autoimmune } \\
\text { phenotypes of snc1 and } \\
\text { bak1 bkk1; (nup96: } \\
\text { nuclear mRNA } \\
\text { accumulation, early } \\
\text { flowering, increased } \\
\text { susceptibility) }\end{array}$ & $\begin{array}{l}\text { Parry et al., 2006; } \\
\text { Wiermer et al., } \\
\text { 2012; Du et al., } \\
\text { 2016; Cheng } \\
\text { et al., } 2020\end{array}$ \\
\hline SEH1 & AT1G64350 & $\begin{array}{l}\text { Essential for autoimmune } \\
\text { phenotypes of snc1 and } \\
\text { bak1 bkk1; (seh1: nuclear } \\
\text { mRNA accumulation, } \\
\text { increased susceptibility) }\end{array}$ & $\begin{array}{l}\text { Wiermer et al., } \\
\text { 2012; Du et al., } \\
2016\end{array}$ \\
\hline NUP85 & AT4G32910 & $\begin{array}{l}\text { Essential for autoimmune } \\
\text { phenotype of bak1 bkk1; } \\
\text { (nup85: nuclear mRNA } \\
\text { accumulation) }\end{array}$ & Du et al., 2016 \\
\hline NUP214 & AT1G55540 & $\begin{array}{l}\text { Interaction with } \\
\text { DEAD-BOX RNA helicase } \\
\text { LOS4; (nup214: embryo } \\
\text { lethality) }\end{array}$ & Braud et al., 2012 \\
\hline RAE1 & AT1G80670 & $\begin{array}{l}\text { Interaction with } \\
\text { DEAD-BOX RNA helicase } \\
\text { GLE1 }\end{array}$ & $\begin{array}{l}\text { Tamura et al., } \\
2010\end{array}$ \\
\hline HOS1 & AT2G39810 & $\begin{array}{l}\text { Interaction with RAE1 and } \\
\text { NUP85; (hos1: nuclear } \\
\text { mRNA accumulation) }\end{array}$ & $\begin{array}{l}\text { Tamura et al., } \\
\text { 2010; MacGregor } \\
\text { et al., 2013; Zhu } \\
\text { et al., 2017 }\end{array}$ \\
\hline CPR5 & AT5G64930 & $\begin{array}{l}\text { (cpr5: nuclear } \\
\text { accumulation of mRNAs } \\
\text { encoding ethylene } \\
\text { signaling factors) }\end{array}$ & Chen et al., 2019 \\
\hline NUP205/EDS4 & AT5G51200 & $\begin{array}{l}\text { (eds4: nuclear } \\
\text { accumulation of mRNAs } \\
\text { encoding circadian clock } \\
\text { and immunity related } \\
\text { factors) }\end{array}$ & $\begin{array}{l}\text { de Leone et al., } \\
2020\end{array}$ \\
\hline
\end{tabular}

the sensitivity of certain signaling pathways to the disruption of particular nucleoporins.

Recently, a function of the NUP107-160 complex was disclosed in autoimmunity and spontaneous cell death activated by the simultaneous loss of the receptor-like kinases (RLKs) BRI1-ASSOCIATED KINASE1 (BAK1) and its closest homolog BAK1-LIKE1 (BKK1; Table 3). Du et al. (2016) show that the bak1 bkk1 double mutant phenotypes genetically depend on NUP160, NUP96, NUP85, and SEH1, as well as the NUP107160 complex interacting DEAD BOX RNA HELICASE1 (DRH1) that is required for nuclear mRNA export (Du et al., 2016). In Nicotiana benthamiana, silencing of the NUP85 homolog NUP75 affects late defense responses to the oomycete pathogen Phytophthora infestans (Ohtsu et al., 2014). Intriguingly, NUP85 and the NUP107-160 complex members NUP133/SYM3 and SEH1/NENA are also essential for symbiotic interactions of the model legume Lotus japonicus (Kanamori et al., 2006; Saito et al., 2007; Groth et al., 2010), substantiating an important role of this nuclear pore sub-complex in plant responses to both symbiotic and pathogenic microorganisms. Whether these functions are regulated by specific signaling events and based on the transport of mRNAs or proteins or on transport-independent functions, or a combination of these processes is a future challenge to address.

\section{Transport-Independent Functions of NPCs and NE-Associated Proteins in Gene Expression and Chromatin Organization}

Transcriptional adaption is a key process in initiating cellular responses to developmental as well as biotic and abiotic signals. Apart from functions in protein and RNA transport processes described above, NPCs together with NE-associated proteins are also involved in the spatial chromatin organization and mediate gene positioning at the nuclear periphery to regulate gene expression and promote mRNA export. The idea of NPCmediated gene regulation was already proposed more than 35 years ago in the "gene gating" hypothesis (Blobel, 1985). Indeed, the sub-nuclear localization of chromatin is correlated to the degree of gene expression, and several examples in yeast and vertebrates provide evidence for direct interactions of nucleoporins with actively transcribed chromatin (Van Bortle and Corces, 2012; Ibarra and Hetzer, 2015).

In plants, limited examples of direct associations between nucleoporins and chromatin have been described. The NUP107160 complex associated HOS1 was shown to interact with the chromosomal FLOWERING LOCUS C (FLC) that acts as a flowering repressor (Figure 4; Jung et al., 2013). Accordingly, mutation of HOS1 results in reduced FLC gene expression in Arabidopsis plants and the early induction of flowering (Lee et al., 2001; Jung et al., 2013). The FLC chromatin binding efficiency to HOS1 is strongly elevated under cold stress conditions and requires FVE, which usually acts as a negative regulator of FLC gene expression (Kim et al., 2004; Jung et al., 2013). The HOS1-FVE complex formed under cold stress inhibits the chromatin binding of HISTONE DEACETYLASE6 (HDA6) that is required for silencing of FLC. The chromatin association of HOS1 therefore leads to suppression of flowering initiation under cold stress (Jung et al., 2013). In another example, HOS1 was shown to positively regulate the expression of miRNA168b by associating with chromatin of the miRNA168b promoter region. 
miRNA168b targets ARGONAUTE1 transcripts, and thus HOS1 may be involved in influencing the activity of the RNA-induced silencing machinery (Wang et al., 2015). HOS1 also associates with members of the NUP107-160 complex, such as NUP85 and NUP160 (Figure 4; Zhu et al., 2017; Cheng et al., 2020), and recently all three nucleoporins were identified as positive regulators of abscisic acid (ABA) and salt stress responses in Arabidopsis (Zhu et al., 2017). Consequently, nup85, hos1 and nup160 mutant plants are hypersensitive to ABA and salt stress and display strongly impaired expression of the respective stressrelated genes (Zhu et al., 2017). It is currently not known whether the nucleoporins of the NUP107-160 complex directly interact with and tether chromatin regions of these stress-related genes to the NPC. Strikingly, subunits of the MED core transcriptional machinery complex associate with NUP85 and directly link RNA polymerase II-mediated transcriptional regulation to this NPC component (Figure 4; Zhu et al., 2017). Further evidence for a positive regulatory function of the NUP107-160 complex in gene expression has been provided by Smith et al. (2015). Artificial tethering of a reporter gene construct to the nuclear periphery via interaction with the NUP107-160 component SEH1 resulted in induced expression of the reporter construct (Smith et al., 2015). In addition, and consistent with immunity defects of nup160 plants, Wiermer et al. (2012) showed that Arabidopsis NUP160 is required for full gene expression of the defense regulator EDS1, but a direct involvement of NUP160 in EDS1 transcriptional regulation at the NPC is unknown.

A potential function in tethering of chromatin to the NPC has also been described for nucleoporins that localize to the nuclear basket. NUA directly associates with SAC3B, a member of the TREX-2 complex, and both components are required for mRNA export (Figure 4; Xu et al., 2007; Yang et al., 2017). However, a loss of NUA and $S A C 3 B$ also leads to reduced transcript abundance of a genome-integrated reporter gene construct (Yang et al., 2017). The authors characterize SAC3B as an anti-silencing factor that prevents heterochromatin formation as an epigenetic silencing mechanism, and potentially tethers chromatin regions to the NPC via its interaction with NUA for enhanced transcriptional activity (Yang et al., 2017).

Based on the reduced expression of reproduction-related genes in nup1/136 mutant plants, Bao et al. (2019) speculate that NUP1/136 directly regulates gene expression via the recruitment of chromatin regions to the NPC. A strongly reduced expression of SA-responsive genes such as the defense marker PATHOGENESIS-RELATED GENE1 (PR1) has also been described for nup1/136 as well as nup82 mutant plants, further supporting a role in transcriptional regulation of these nucleoporins (Tamura et al., 2017). Using restriction enzymemediated chromatin immunoprecipitation (RE-ChIP) assays with NUP1/136-GFP as bait, Bi et al. (2017) demonstrated that NUP1 is primarily associated with transcriptionally repressed chromatin region. However, some highly expressed genes were also enriched in NUP1/136-GFP precipitated chromatin regions, consistent with a subset of these genes showing reduced expression in nup1/136 mutant plants (Bi et al., 2017; Tamura et al., 2017). This suggests a different degree to which gene expression can be modulated by NUP1/136 and may thus involve additional factors that associate with a particular chromosomal locus.

Detailed studies in animal systems have demonstrated that repressed chromatin regions found at the nuclear periphery often associate with lamins and are therefore termed lamin-associated domains (LADs; Pickersgill et al., 2006; Guelen et al., 2008; Ikegami et al., 2010; Peric-Hupkes et al., 2010; van Steensel and Belmont, 2017). Lamins are part of the nucleoskeleton at the inner side of the NE, interact with NE localized membrane proteins and are functionally required in determining nuclear shape and nuclear positioning (Groves et al., 2020). Although plants do not encode for canonical lamins, plant specific structural and functional equivalents can be found and have been termed nuclear matrix constituent proteins (NMCPs; Dittmer et al., 2007; Sakamoto and Takagi, 2013; Wang et al., 2013; Ciska and Moreno Díaz de la Espina, 2014; Kimura et al., 2014; Meier et al., 2017; Sakamoto et al., 2020). In Arabidopsis, NMCPs considered to fulfill lamin-like functions are named CROWDED NUCLEI (CRWN) 1-4 (Dittmer et al., 2007; Wang et al., 2013). Indeed, CRWN1 directly interacts with INM associated proteins and, like CRWN2-4, can be found at the nuclear periphery where these proteins form a meshwork structure (Figure 4), while CRWN2 and CRWN3 are also present in the nuclear interior (Dittmer et al., 2007; Sakamoto and Takagi, 2013; Graumann, 2014; Sakamoto et al., 2020). As for their animal equivalents, CRWN proteins play a role in determining the nuclear shape since crwn mutant plants display abnormally shaped or small nuclei (Wang et al., 2013). A role in tethering heterochromatin regions to the NE - which were previously also identified by ChIP assays with NUP1/136-GFP has been demonstrated for CRWN1 and CRWN4, providing a potential link between the NPC and plant lamin-like proteins in positioning chromatin at the nuclear periphery (Hu et al., 2019). Significantly, CRWN1 and CRWN4 can also be found in complex with PROLINE-TRYPTOPHANE-TRYPTOPHANE-PROLINE (PWWP) INTERACTOR OF POLYCOMBS1 (PWO1), a component of the repressive Polycomb-Group (PcG) complex that associates with repressed chromatin regions, further outlining a role of these CRWN proteins in gene repression in plants (Mikulski et al., 2019).

It has been reported that CRWN1 directly interacts with the transcription factor NAC WITH TRANSMEMBRANE MOTIF1LIKE9 (NTL9) and the transcriptional repressor SUPPRESSOR OF NPR1-1, INDUCIBLE1 (SNI1), thereby repressing PR1 gene expression (Guo et al., 2017). Consequently, crwn1 and crwn 1 crwn 2 double mutant plants show elevated defense gene expression, leading to enhanced resistance to Pseudomonas bacteria (Guo et al., 2017). Similarly, Choi et al. (2019) reported an enhanced PR1 gene expression in crwn1 crwn2 as well as in crwn1 crwn4 double mutant plants. Both double mutant lines display enhanced resistance to Pseudomonas bacteria, albeit no enhanced resistance was observed for either of the single mutant lines. Strikingly, crwn 1 crwn 2 and crwn 1 crwn 4 double mutants show elevated levels of SA due to the enhanced expression of SA biosynthesis genes and master transcription factors regulating genes of the SA-defense pathway (Choi et al., 2019). In crwn1 crwn2, this correlated with reduced histone 


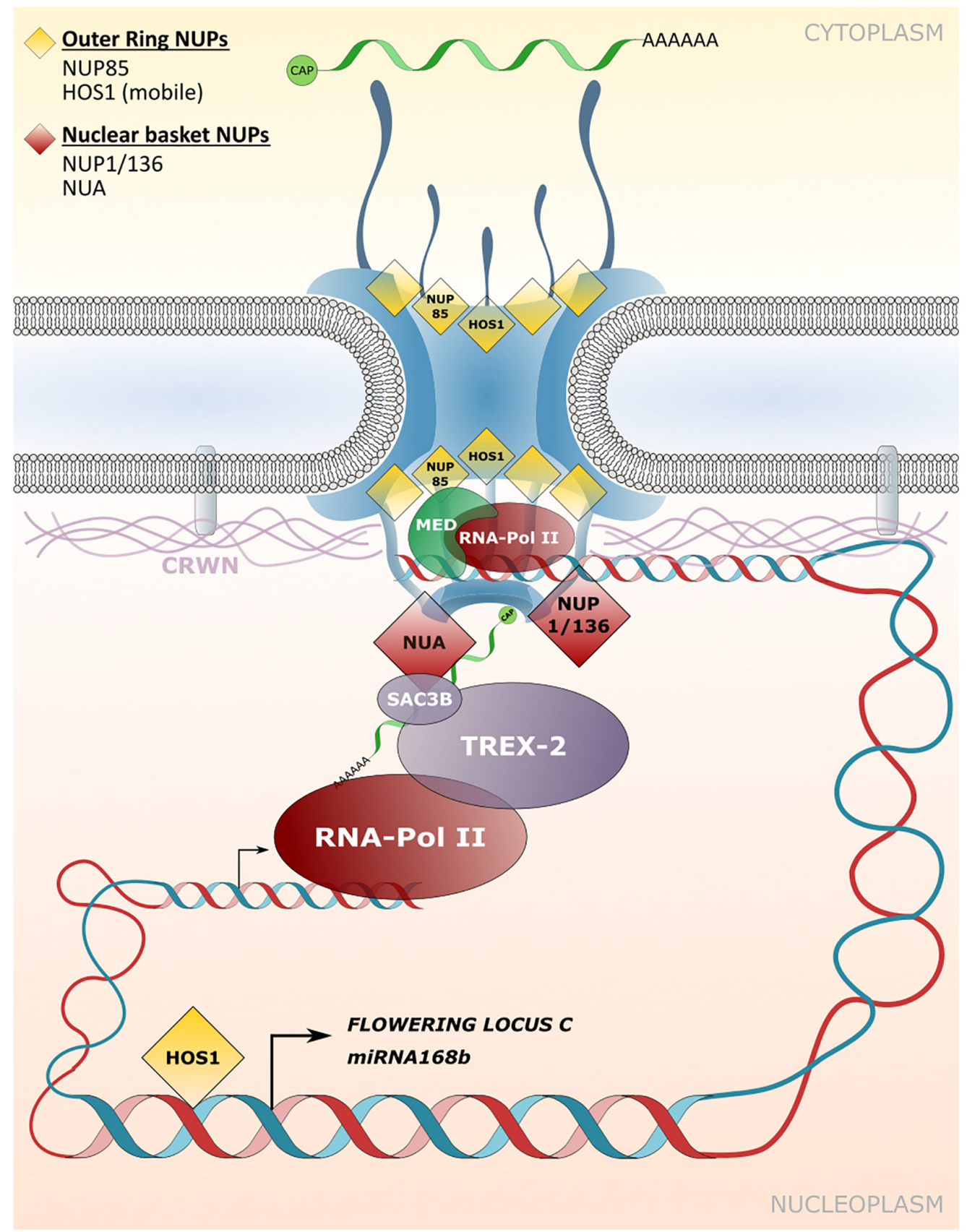

FIGURE 4 | Transport independent functions of NPCs and NE-associated protein functions in gene expression and chromatin organization. Nucleoporins and nuclear matrix constituent proteins such as CROWDED NUCLEI (CRWN) in Arabidopsis that are implicated in tethering chromatin regions to the NPC/INM or in associating with transcriptional regulators are shown. These interactions influence transcriptional responses independently of - or in addition to - NPC functions in macromolecular transport between the cytoplasm and the nucleoplasm.

modifications in chromatin regions encoding for a subset of these defense genes, further arguing for a direct repression of chromatin regions via CRWN-mediated tethering to the nuclear periphery (Choi and Richards, 2020).

It is noteworthy that Choi et al. (2019) consistently observed intermediate defense-associated phenotypes of the crwn 1 crwn 4 double mutant when compared to wild-type plants and the crwn 1 crwn 2 mutant, outlining differential and - on global gene expression patterns - partially antagonistic functions for the CRWN proteins on transcription. In another recent study, crwn1 mutants show elevated levels of jasmonic acid (JA), a plant hormone required for defense against necrotrophic pathogens that kill host tissues (Jarad et al., 2020). This molecular phenotype of crwn1 mutant plants correlates with enhanced 
resistance toward the necrotrophic fungus $B$. cinerea (Jarad et al., 2020). In contrast, crwn 1 plants are more susceptible to nonvirulent Pseudomonas bacteria and show defects in early defense responses (Jarad et al., 2020). These results outline the important role of plant lamin-like proteins in the transcriptional regulation of multiple defense pathways.

Apart from the effect on immune responses, mutations in $C R W N$ genes also affect developmental processes such as seed germination, since crwn 1 crwn3 double mutant plants show reduced germination rates and are hypersensitive to ABA (Zhao et al., 2016). The authors demonstrate that CRWN1 and CRWN3 participate in the degradation of $\mathrm{ABI} 5$, a positive regulator in the ABA signaling pathway that activates the expression of ABAresponsive genes. In addition, it has been demonstrated that the crwn 1 crwn 4 double mutant displays low copper tolerance (Sakamoto et al., 2020). Indeed, CRWN1 is required for the positioning of copper responsive gene clusters on chromosome 5 to the nuclear periphery in order to enhance transcriptional responses under copper induced stress (Sakamoto et al., 2020).

The examples summarized in this chapter demonstrate that the tethering of chromatin to the nuclear periphery via NPCs or plant lamin-like proteins can have suppressive as well as enhancing consequences on gene expression depending on the specific locus or stimulus. Given that some crwn mutant combinations have partially antagonistic effects on global gene expression patterns (Choi et al., 2019), it will be informative to investigate the functional interplay between the different CRWN proteins and NPCs as well as other components associated with the NE for their roles in regulating gene expression changes and epigenetic transcriptional modifications/memory in response to stimulus perception.

\section{CONCLUDING REMARKS}

The work reviewed here emphasizes the plant NPC and its associated transport machinery as an important hub that actively regulates cellular signaling pathways and gene expression as part of developmental programs and in response to environmental factors. Recent work has made significant progress in defining the NPC/NE proteomes, identifying NTR cargo substrates, and in assigning nucleoporin and NTR functions to multiple plant signaling pathways. However, many of the molecular mechanisms underpinning transport-associated

\section{REFERENCES}

Ashkenazy-Titelman, A., Shav-Tal, Y., and Kehlenbach, R. H. (2020). Into the basket and beyond: the journey of mRNA through the nuclear pore complex. Biochem. J. 477, 23-44. doi: 10.1042/BCJ20190132

Bai, X., Correa, V. R., Toruño, T. Y., Ammar, E.-D., Kamoun, S., and Hogenhout, S. A. (2008). AY-WB phytoplasma secretes a protein that targets plant cell nuclei. Mol. Plant Microbe Interact. 22, 18-30. doi: 10.1094/MPMI-22-1-0018

Bao, S., Shen, G., Li, G., Liu, Z., Arif, M., Wei, Q., et al. (2019). The Arabidopsis nucleoporin NUP1 is essential for megasporogenesis and early stages of pollen development. Plant Cell Rep. 38, 59-74. doi: 10.1007/s00299-018-2349-7

Bhattacharjee, S., Lee, L.-Y., Oltmanns, H., Cao, H., Veena, Cuperus, J., et al. (2008). IMPa-4, an Arabidopsis importin $\alpha$ isoform, is preferentially involved and -independent processes in developmental and environmental stress pathways remain to be determined. In particular, open questions to be addressed include: What are the steady-state and stimulus-specific "transportomes" of NTRs and how are NTR cargo binding specificities and transport kinetics across the NPC regulated? Is the nuclear translocation of small molecules, such as plant hormones, diffusion based or actively regulated by binding to transported carrier proteins? What are the effects of positioning particular genes in proximity to the NPC/NE on their expression and epigenetic regulation? How is the recruitment of a certain chromosomal locus regulated, considering that each nucleus contains a multitude of NPCs? Are there tissue/celltype specific differences in NPC composition and/or posttranslational nucleoporin modifications that may account for the involvement in particular response pathways? And finally, is the protein composition of NPCs within a single nucleus identical or variable, and does variability provide sub-populations of NPCs with specific functions? Elucidating these questions will provide valuable insights into the intricate regulation of cellular gene expression and signal transduction pathways by nucleocytoplasmic transport and transport-independent NPC functions in plants.

\section{AUTHOR CONTRIBUTIONS}

DL and MW conceived the review. DL, PFWR, and MW wrote the manuscript. PFWR prepared the figures and tables. All authors edited and approved the submitted version of the article.

\section{FUNDING}

We acknowledge funding of our research by the Deutsche Forschungsgemeinschaft (DFG) research grant WI 3208/8-1 and the DFG-funded IRTG 2172 "PRoTECT" program of the Göttingen Graduate Center of Neurosciences, Biophysics, and Molecular Biosciences.

\section{ACKNOWLEDGMENTS}

We thank Lennart Wirthmueller (IPB Halle, Germany) for valuable discussions and critical reading of the manuscript.

in agrobacterium-mediated plant transformation. Plant Cell 20:2661. doi: 10. 1105/tpc.108.060467

Bi, X., Cheng, Y.-J., Hu, B., Ma, X., Wu, R., Wang, J.-W., et al. (2017). Nonrandom domain organization of the Arabidopsis genome at the nuclear periphery. Genome Res. 27, 1162-1173. doi: 10.1101/gr.215186.116

Blanvillain, R., Boavida, L. C., McCormick, S., and Ow, D. W. (2008). EXPORTIN1 genes are essential for development and function of the gametophytes in Arabidopsis thaliana. Genetics 180, 1493-1500. doi: 10.1534/genetics.108. 094896

Blobel, G. (1985). Gene gating: a hypothesis. Proc. Natl. Acad. Sci. U.S.A. 82, 8527-8529. doi: 10.1073/pnas.82.24.8527

Bollman, K. M., Aukerman, M. J., Park, M.-Y., Hunter, C., Berardini, T. Z., and Poethig, R. S. (2003). HASTY, the Arabidopsis ortholog of exportin 5/MSN5, 
regulates phase change and morphogenesis. Development 130:1493. doi: 10. 1242/dev.00362

Bologna, N. G., Iselin, R., Abriata, L. A., Sarazin, A., Pumplin, N., Jay, F., et al. (2018). Nucleo-cytosolic shuttling of ARGONAUTE1 prompts a revised model of the plant MicroRNA pathway. Mol. Cell 69, 709-719.e5. doi: 10.1016/j. molcel.2018.01.007

Braud, C., Zheng, W., and Xiao, W. (2012). LONO1 encoding a nucleoporin is required for embryogenesis and seed viability in Arabidopsis. Plant Physiol. 160, 823-836. doi: 10.1104/pp.112.202192

Cai, Q., Liang, C., Wang, S., Hou, Y., Gao, L., Liu, L., et al. (2018). The disease resistance protein SNC1 represses the biogenesis of microRNAs and phased siRNAs. Nat. Commun. 9:5080. doi: 10.1038/s41467-018-07516-Z

Cambiagno, D. A., Giudicatti, A. J., Arce, A. L., Gagliardi, D., Li, L., Yuan, W., et al. (2020). HASTY modulates miRNA biogenesis by linking pri-miRNA transcription and processing. Mol. Plant. 14, 426-439. doi: 10.1016/j.molp.2020. 12.019

Chakraborty, P., Wang, Y., Wei, J.-H., van Deursen, J., Yu, H., Malureanu, L., et al. (2008). Nucleoporin levels regulate cell cycle progression and phase-specific gene expression. Dev. Cell 15, 657-667. doi: 10.1016/j.devcel.2008.08.020

Chen, C., Kim, D., Yun, H. R., Lee, Y. M., Yogendra, B., Bo, Z., et al. (2020). Nuclear import of LIKE HETEROCHROMATIN PROTEIN1 is redundantly mediated by importins $\alpha-1, \alpha-2$ and $\alpha-3$. Plant J. 103, 1205-1214. doi: 10.1111/tpj.14796

Chen, C., Masi, R. D., Lintermann, R., and Wirthmueller, L. (2018). Nuclear import of Arabidopsis poly(ADP-Ribose) polymerase 2 is mediated by importin- $\alpha$ and a nuclear localization sequence located between the predicted SAP domains. Front. Plant Sci. 9:1581. doi: 10.3389/fpls.2018.01581

Chen, J., Yu, Y., Sui, X., Qiao, L., and Dong, C.-H. (2019). Arabidopsis CPR5 regulates ethylene signaling via interacting with ETR1 $\mathrm{N}$-terminus and controlling mRNAs nucleocytoplasmic transport. bioRxiv [Preprint]. doi: 10 . $1101 / 862862$

Cheng, Y. T., Germain, H., Wiermer, M., Bi, D., Xu, F., García, A. V., et al. (2009). Nuclear pore complex component MOS7/Nup88 is required for innate immunity and nuclear accumulation of defense regulators in Arabidopsis. Plant Cell 21, 2503-2516. doi: 10.1105/tpc.108.064519

Cheng, Z., Zhang, X., Huang, P., Huang, G., Zhu, J., Chen, F., et al. (2020). Nup96 and HOS1 are mutually stabilized and gate CONSTANS protein level, conferring long-day photoperiodic flowering regulation in Arabidopsis. Plant Cell 32, 374-391. doi: 10.1105/tpc.19.00661

Choi, J., and Richards, E. J. (2020). The role of CRWN nuclear proteins in chromatin-based regulation of stress response genes. Plant Signal. Behav. 15:1694224. doi: 10.1080/15592324.2019.1694224

Choi, J., Strickler, S. R., and Richards, E. J. (2019). Loss of CRWN nuclear proteins induces cell death and salicylic acid defense signaling. Plant Physiol. 179, 1315-1329. doi: 10.1104/pp.18.01020

Christie, M., Chang, C.-W., Róna, G., Smith, K. M., Stewart, A. G., Takeda, A. A. S., et al. (2016). Structural biology and regulation of protein import into the nucleus. J. Mol. Biol. 428, 2060-2090. doi: 10.1016/j.jmb.2015.10.023

Ciska, M., and Moreno Díaz de la Espina, S. (2014). The intriguing plant nuclear lamina. Front. Plant Sci. 5:166. doi: 10.3389/fpls.2014.00166

Contreras, R., Kallemi, P., González-García, M. P., Lazarova, A., Sánchez-Serrano, J. J., Sanmartín, M., et al. (2019). Identification of domains and factors involved in MINIYO nuclear import. Front. Plant Sci. 10:1044. doi: 10.3389/fpls.2019. 01044

de Leone, M. J., Hernando, C. E., Romanowski, A., Careno, D. A., Soverna, A. F., Sun, H., et al. (2020). Bacterial infection disrupts clock gene expression to attenuate immune responses. Curr. Biol. 30, 1740-1747.e6. doi: 10.1016/j.cub. 2020.02.058

Dittmer, T. A., Stacey, N. J., Sugimoto-Shirasu, K., and Richards, E. J. (2007). LITTLE NUCLEI genes affecting nuclear morphology in Arabidopsis thaliana. Plant Cell 19, 2793-2803. doi: 10.1105/tpc.107.053231

Dong, C.-H., Agarwal, M., Zhang, Y., Xie, Q., and Zhu, J.-K. (2006a). The negative regulator of plant cold responses, HOS1, is a RING E3 ligase that mediates the ubiquitination and degradation of ICE1. Proc. Natl. Acad. Sci. U.S.A. 103, 8281-8186. doi: 10.1073/pnas.0602874103

Dong, C.-H., Hu, X., Tang, W., Zheng, X., Kim, Y. S., Lee, B., et al. (2006b). A Putative Arabidopsis nucleoporin, AtNUP160, is critical for RNA export and required for plant tolerance to cold stress. Mol. Cell. Biol. 26, 9533-9543. doi: 10.1128/MCB.01063-06
Du, J., Gao, Y., Zhan, Y., Zhang, S., Wu, Y., Xiao, Y., et al. (2016). Nucleocytoplasmic trafficking is essential for BAK1- and BKK1-mediated celldeath control. Plant J. 85, 520-531. doi: 10.1111/tpj.13125

Ehrnsberger, H. F., Grasser, M., and Grasser, K. D. (2019). Nucleocytosolic mRNA transport in plants: export factors and their influence on growth and development. J. Exp. Bot. 70, 3757-3763. doi: 10.1093/jxb/erz173

Feys, B. J., Wiermer, M., Bhat, R. A., Moisan, L. J., Medina-Escobar, N., Neu, C., et al. (2005). Arabidopsis SENESCENCE-ASSOCIATED GENE101 stabilizes and signals within an ENHANCED DISEASE SUSCEPTIBILITY1 complex in plant innate immunity. Plant Cell 17, 2601-2613. doi: 10.1105/tpc.105.033910

Gallemí, M., Galstyan, A., Paulišić, S., Then, C., Ferrández-Ayela, A., Lorenzo-Orts, L., et al. (2016). DRACULA2 is a dynamic nucleoporin with a role in regulating the shade avoidance syndrome in Arabidopsis. Development 143, 1623-1631. doi: 10.1242/dev.130211

Ganguly, A., DeMott, L., Zhu, C., McClosky, D. D., Anderson, C. T., and Dixit, R. (2018). Importin- $\beta$ directly regulates the motor activity and turnover of a kinesin-4. Dev. Cell 44, 642-651. doi: 10.1016/j.devcel.2018.01.027

Gao, Y., Gong, X., Cao, W., Zhao, J., Fu, L., Wang, X., et al. (2008). SAD2 in Arabidopsis functions in trichome initiation through mediating GL3 function and regulating GL1, TTG1 and GL2 expression. J. Integr. Plant Biol. 50, 906-917. doi: 10.1111/j.1744-7909.2008.00695.x

García, A. V., Blanvillain-Baufumé, S., Huibers, R. P., Wiermer, M., Li, G., Gobbato, E., et al. (2010). Balanced nuclear and cytoplasmic activities of EDS1 are required for a complete plant innate immune response. PLoS Pathog. 6:e1000970. doi: 10.1371/journal.ppat.1000970

Genenncher, B., Wirthmueller, L., Roth, C., Klenke, M., Ma, L., Sharon, A., et al. (2016). Nucleoporin-regulated MAP kinase signaling in immunity to a necrotrophic fungal pathogen. Plant Physiol. 172, 1293-1305. doi: 10.1104/pp. 16.00832

Germain, H., Qu, N., Cheng, Y. T., Lee, E., Huang, Y., Dong, O. X., et al. (2010). MOS11: a new component in the mRNA export pathway. PLoS Genet. 6:e1001250. doi: 10.1371/journal.pgen.1001250

Gerth, K., Lin, F., Daamen, F., Menzel, W., Heinrich, F., and Heilmann, M. (2017). Arabidopsis phosphatidylinositol 4-phosphate 5-kinase 2 contains a functional nuclear localization sequence and interacts with alpha-importins. Plant J. 92, 862-878. doi: 10.1111/tpj.13724

Gong, Z., Lee, H., Xiong, L., Jagendorf, A., Stevenson, B., and Zhu, J.-K. (2002). RNA helicase-like protein as an early regulator of transcription factors for plant chilling and freezing tolerance. Proc. Natl. Acad. Sci. U.S.A. 99, 11507-11512. doi: 10.1073 /pnas.172399299

Graumann, K. (2014). Evidence for LINC1-SUN associations at the plant nuclear periphery. PLoS One 9:e93406. doi: 10.1371/journal.pone.0093406

Griffis, E. R., Altan, N., Lippincott-Schwartz, J., and Powers, M. A. (2002). Nup98 is a mobile nucleoporin with transcription-dependent dynamics. Mol. Biol. Cell 13, 1282-1297. doi: 10.1091/mbc.01-11-0538

Groth, M., Takeda, N., Perry, J., Uchida, H., Dräxl, S., Brachmann, A., et al. (2010). NENA, a Lotus japonicus homolog of sec13, is required for rhizodermal infection by arbuscular mycorrhiza fungi and rhizobia but dispensable for cortical endosymbiotic development. Plant Cell 22, 2509. doi: 10.1105/tpc.109. 069807

Groves, N. R., Biel, A., Moser, M., Mendes, T., Amstutz, K., and Meier, I. (2020). Recent advances in understanding the biological roles of the plant nuclear envelope. Nucleus 11, 330-346. doi: 10.1080/19491034.2020.1846836

Grüter, P., Tabernero, C., von Kobbe, C., Schmitt, C., Saavedra, C., Bachi, A., et al. (1998). TAP, the human homolog of Mex67p, mediates CTE-dependent RNA export from the nucleus. Mol. Cell 1, 649-659. doi: 10.1016/S1097-2765(00) 80065-9

Gu, Y., Zebell, S. G., Liang, Z., Wang, S., Kang, B.-H., and Dong, X. (2016). Nuclear pore permeabilization is a convergent signaling event in effector-triggered immunity. Cell 166, 1526-1538.e11. doi: 10.1016/j.cell.2016.07.042

Guelen, L., Pagie, L., Brasset, E., Meuleman, W., Faza, M. B., Talhout, W., et al. (2008). Domain organization of human chromosomes revealed by mapping of nuclear lamina interactions. Nature 453, 948-951. doi: 10.1038/nature06947

Guo, T., Mao, X., Zhang, H., Zhang, Y., Fu, M., Sun, Z., et al. (2017). Lamin-like proteins negatively regulate plant immunity through NAC WITH TRANSMEMBRANE MOTIF1-LIKE9 and NONEXPRESSOR OF PR GENES1 in Arabidopsis thaliana. Mol. Plant 10, 1334-1348. doi: 10.1016/j.molp.2017. 09.008 
Helizon, H., Rösler-Dalton, J., Gasch, P., von Horsten, S., Essen, L.-O., and Zeidler, M. (2018). Arabidopsis phytochrome A nuclear translocation is mediated by a far-red elongated hypocotyl 1-importin complex. Plant J. 96, 1255-1268. doi: 10.1111 tpj.14107

Herud, O., Weijers, D., Lau, S., and Jürgens, G. (2016). Auxin responsiveness of the MONOPTEROS-BODENLOS module in primary root initiation critically depends on the nuclear import kinetics of the Aux/IAA inhibitor BODENLOS. Plant J. 85, 269-277. doi: 10.1111/tpj.13108

Hieronymus, H., and Silver, P. A. (2003). Genome-wide analysis of RNA-protein interactions illustrates specificity of the mRNA export machinery. Nat. Genet. 33, 155-161. doi: 10.1038/ng1080

Hu, B., Wang, N., Bi, X., Karaaslan, E. S., Weber, A.-L., Zhu, W., et al. (2019). Plant lamin-like proteins mediate chromatin tethering at the nuclear periphery. Genome Biol. 20:87. doi: 10.1186/s13059-019-1694-3

Hunter, C. A., Aukerman, M. J., Sun, H., Fokina, M., and Poethig, R. S. (2003). PAUSED encodes the Arabidopsis exportin-t ortholog. Plant Physiol. 132, 21352143. doi: 10.1104/pp.103.023309

Ibarra, A., and Hetzer, M. W. (2015). Nuclear pore proteins and the control of genome functions. Genes Dev. 29, 337-349. doi: 10.1101/gad.256495.114

Ikegami, K., Egelhofer, T. A., Strome, S., and Lieb, J. D. (2010). Caenorhabditis elegans chromosome arms are anchored to the nuclear membrane via discontinuous association with LEM-2. Genome Biol. 11:R120. doi: 10.1186/gb2010-11-12-r120

Jacob, Y., Mongkolsiriwatana, C., Veley, K. M., Kim, S. Y., and Michaels, S. D. (2007). The nuclear pore protein AtTPR is required for RNA homeostasis, flowering time, and auxin signaling. Plant Physiol. 144, 1383-1390. doi: 10. 1104/pp.107.100735

Jarad, M., Mariappan, K., Almeida-Trapp, M., Mette, M. F., Mithöfer, A., Rayapuram, N., et al. (2020). The lamin-like LITTLE NUCLEI 1 (LINC1) regulates pattern-triggered immunity and jasmonic acid signaling. Front. Plant Sci. 10:1639. doi: 10.3389/fpls.2019.01639

Jiang, C.-J., Shoji, K., Matsuki, R., Baba, A., Inagaki, N., Ban, H., et al. (2001). Molecular cloning of a novel importin $\alpha$ homologue from rice, by which constitutive photomorphogenic 1 (COP1) nuclear localization signal (NLS)protein is preferentially nuclear imported. J. Biol. Chem. 276, 9322-9329. doi: 10.1074/jbc.M006430200

Jiang, S., Xiao, L., Huang, P., Cheng, Z., Chen, F., Miao, Y., et al. (2020). Nucleoporin Nup98 participates in flowering regulation in a CONSTANS independent mode. Plant Cell Rep. 39, 687-689. doi: 10.1007/s00299-02002514-2

Jung, J.-H., Park, J.-H., Lee, S., To, T. K., Kim, J.-M., Seki, M., et al. (2013). The cold signaling attenuator HIGH EXPRESSION OF OSMOTICALLY RESPONSIVE GENE1 Activates FLOWERING LOCUS C transcription via chromatin remodeling under short-term cold stress in Arabidopsis. Plant Cell 25, 4378-4390. doi: 10.1105/tpc.113.118364

Kalverda, B., Pickersgill, H., Shloma, V. V., and Fornerod, M. (2010). Nucleoporins directly stimulate expression of developmental and cell-cycle genes inside the nucleoplasm. Cell 140, 360-371. doi: 10.1016/j.cell.2010.01.011

Kanamori, N., Madsen, L. H., Radutoiu, S., Frantescu, M., Quistgaard, E. M. H., Miwa, H., et al. (2006). A nucleoporin is required for induction of $\mathrm{Ca} 2+$ spiking in legume nodule development and essential for rhizobial and fungal symbiosis. Proc. Natl. Acad. Sci. U.S.A. 103, 359-364. doi: 10.1073/pnas.0508883103

Kanneganti, T.-D., Bai, X., Tsai, C.-W., Win, J., Meulia, T., Goodin, M., et al. (2007). A functional genetic assay for nuclear trafficking in plants. Plant J. 50, 149-158. doi: 10.1111/j.1365-313X.2007.03029.x

Katahira, J. (2012). mRNA export and the TREX complex. Biochim. Biophys. Acta 1819, 507-513. doi: 10.1016/j.bbagrm.2011.12.001

Kim, H.-J., Hyun, Y., Park, J.-Y., Park, M.-J., Park, M.-K., Kim, M. D., et al. (2004). A genetic link between cold responses and flowering time through FVE in Arabidopsis thaliana. Nat. Genet. 36, 167-171. doi: 10.1038/ng1298

Kim Guisbert, K., Duncan, K., Li, H., and Guthrie, C. (2005). Functional specificity of shuttling hnRNPs revealed by genome-wide analysis of their RNA binding profiles. RNA 11, 383-393. doi: 10.1261/rna.7234205

Kimura, Y., Fujino, K., Ogawa, K., and Masuda, K. (2014). Localization of Daucus carota NMCP1 to the nuclear periphery: the role of the N-terminal region and an NLS-linked sequence motif, RYNLRR, in the tail domain. Front. Plant Sci. 5:62. doi: $10.3389 /$ fpls.2014.00062
Köhler, A., and Hurt, E. (2007). Exporting RNA from the nucleus to the cytoplasm. Nat. Rev. Mol. Cell Biol. 8, 761-773. doi: 10.1038/nrm2255

Kutay, U., and Güttinger, S. (2005). Leucine-rich nuclear-export signals: born to be weak. Trends Cell Biol. 15, 121-124. doi: 10.1016/j.tcb.2005.01.005

Lee, H., Xiong, L., Gong, Z., Ishitani, M., Stevenson, B., and Zhu, J.-K. (2001). The Arabidopsis HOS1 gene negatively regulates cold signal transduction and encodes a RING finger protein that displays cold-regulated nucleo-cytoplasmic partitioning. Genes Dev. 15, 912-924. doi: 10.1101/gad.866801

Lee, H.-S., Lee, D.-H., Cho, H. K., Kim, S. H., Auh, J. H., and Pai, H.-S. (2015). InsP6-sensitive variants of the Gle1 mRNA export factor rescue growth and fertility defects of the ipk1 low-phytic-acid mutation in Arabidopsis. Plant Cell 27, 417-431. doi: 10.1105/tpc.114.132134

Li, C., Liu, L., Teo, Z. W. N., Shen, L., and Yu, H. (2020). Nucleoporin 160 regulates flowering through anchoring HOS1 for destabilizing CO in Arabidopsis. Plant Commun. 1:100033. doi: 10.1016/j.xplc.2020.100033

Li, J., and Chen, X. (2003). PAUSED, a putative exportin-t, acts pleiotropically in Arabidopsis development but is dispensable for viability. Plant Physiol. 132, 1913-1924. doi: 10.1104/pp.103.023291

Liu, H.-H., Xiong, F., Duan, C.-Y., Wu, Y.-N., Zhang, Y., and Li, S. (2019). Importin $\beta 4$ mediates nuclear import of GRF-interacting factors to control ovule development in Arabidopsis. Plant Physiol. 179, 1080-1092. doi: 10.1104/ pp.18.01135

Lu, Q., Tang, X., Tian, G., Wang, F., Liu, K., Nguyen, V., et al. (2010). Arabidopsis homolog of the yeast TREX-2 mRNA export complex: components and anchoring nucleoporin. Plant J. 61, 259-270. doi: 10.1111/j.1365-313X.2009. 04048.x

Lüdke, D., Roth, C., Kamrad, S. A., Messerschmidt, J., Hartken, D., Appel, J., et al. (2021). Functional requirement of the Arabidopsis importin- $\alpha$ nuclear transport receptor family in autoimmunity mediated by the NLR protein SNC1. Plant J. 105, 994-1009. doi: 10.1111/tpj.15082

Luo, Y., Wang, Z., Ji, H., Fang, H., Wang, S., Tian, L., et al. (2013). An Arabidopsis homolog of importin $\beta 1$ is required for ABA response and drought tolerance. Plant J. 75, 377-389. doi: 10.1111/tpj.12207

MacGregor, D. R., Gould, P., Foreman, J., Griffiths, J., Bird, S., Page, R., et al. (2013). HIGH EXPRESSION OF OSMOTICALLY RESPONSIVE GENES1 is required for circadian periodicity through the promotion of nucleo-cytoplasmic mRNA export in Arabidopsis. Plant Cell 25, 4391-4404. doi: 10.1105/tpc.113.114959

Masuda, S., Das, R., Cheng, H., Hurt, E., Dorman, N., and Reed, R. (2005). Recruitment of the human TREX complex to mRNA during splicing. Genes Dev. 19, 1512-1517. doi: 10.1101/gad.1302205

Meier, I., Richards, E. J., and Evans, D. E. (2017). Cell biology of the plant nucleus. Annu. Rev. Plant Biol. 68, 139-172. doi: 10.1146/annurev-arplant-042916041115

Meinke, D., Muralla, R., Sweeney, C., and Dickerman, A. (2008). Identifying essential genes in Arabidopsis thaliana. Trends Plant Sci. 13, 483-491. doi: 10.1016/j.tplants.2008.06.003

Mikulski, P., Hohenstatt, M. L., Farrona, S., Smaczniak, C., Stahl, Y., Kalyanikrishna, et al. (2019). The chromatin-associated protein PWO1 interacts with plant nuclear lamin-like components to regulate nuclear size. Plant Cell 31, 1141-1154. doi: 10.1105/tpc.18.00663

Moore, M. J. (2005). From birth to death: the complex lives of eukaryotic mRNAs. Science 309, 1514-1518. doi: 10.1126/science.1111443

Mou, Z., Fan, W., and Dong, X. (2003). Inducers of plant systemic acquired resistance regulate NPR1 function through redox changes. Cell 113, 935-944. doi: 10.1016/S0092-8674(03)00429-X

Muñoz, A., Mangano, S., González-García, M. P., Contreras, R., Sauer, M., De Rybel, B., et al. (2017). RIMA-dependent nuclear accumulation of IYO triggers auxin-irreversible cell differentiation in Arabidopsis. Plant Cell 29, 575-588. doi: $10.1105 /$ tpc. 16.00791

Nielsen, E. (2020). The small GTPase superfamily in plants: a conserved regulatory module with novel functions. Annu. Rev. Plant Biol. 71, 247-272. doi: 10.1146/ annurev-arplant-112619-025827

Obado, S. O., Brillantes, M., Uryu, K., Zhang, W., Ketaren, N. E., Chait, B. T., et al. (2016). Interactome mapping reveals the evolutionary history of the nuclear pore complex. PLoS Biol. 14:e1002365. doi: 10.1371/journal.pbio.1002365

Oh, T. R., Yu, S. G., Yang, H. W., Kim, J. H., and Kim, W. T. (2020). AtKPNB1, an Arabidopsis importin- $\beta$ protein, is downstream of the RING E3 ubiquitin 
ligase AtAIRP1 in the ABA-mediated drought stress response. Planta 252:93. doi: 10.1007/s00425-020-03500-4

Ohtsu, M., Shibata, Y., Ojika, M., Tamura, K., Hara-Nishimura, I., Mori, H., et al. (2014). Nucleoporin 75 is involved in the ethylene-mediated production of phytoalexin for the resistance of Nicotiana benthamiana to Phytophthora infestans. Mol. Plant Microbe Interact. 27, 1318-1330. doi: 10.1094/MPMI-0614-0181-R

Palma, K., Zhang, Y., and Li, X. (2005). An importin $\alpha$ homolog, MOS6, plays an important role in plant innate immunity. Curr. Biol. 15, 1129-1135. doi: 10.1016/j.cub.2005.05.022

Pan, H., Liu, S., and Tang, D. (2012a). HPR1, a component of the THO/TREX complex, plays an important role in disease resistance and senescence in Arabidopsis. Plant J. 69, 831-843. doi: 10.1111/j.1365-313X.2011.04835.x

Pan, H., Liu, S., and Tang, D. (2012b). The THO/TREX complex functions in disease resistance in Arabidopsis. Plant Signal. Behav. 7, 422-424. doi: 10.4161/ psb. 18991

Panda, C., Li, X., Wager, A., Chen, H.-Y., and Li, X. (2020). An importin-beta-like protein mediates lignin-modification-induced dwarfism in Arabidopsis. Plant J. 102, 1281-1293. doi: 10.1111/tpj.14701

Park, G. T., Frost, J. M., Park, J.-S., Kim, T. H., Lee, J. S., Oh, S. A., et al. (2014). Nucleoporin MOS7/Nup88 is required for mitosis in gametogenesis and seed development in Arabidopsis. Proc. Natl. Acad. Sci. U.S.A. 111, 18393-18398. doi: $10.1073 /$ pnas. 1421911112

Park, M. Y., Wu, G., Gonzalez-Sulser, A., Vaucheret, H., and Poethig, R. S. (2005). Nuclear processing and export of microRNAs in Arabidopsis. Proc. Natl. Acad. Sci. U.S.A. 102, 3691-3696. doi: 10.1073/pnas.0405570102

Parry, G. (2014). Components of the Arabidopsis nuclear pore complex play multiple diverse roles in control of plant growth. J. Exp. Bot. 65, 6057-6067. doi: $10.1093 /$ jxb/eru346

Parry, G., Ward, S., Cernac, A., Dharmasiri, S., and Estelle, M. (2006). The Arabidopsis SUPPRESSOR OF AUXIN RESISTANCE proteins are nucleoporins with an important role in hormone signaling and development. Plant Cell 18, 1590-1603. doi: 10.1105/tpc.106.041566

Peric-Hupkes, D., Meuleman, W., Pagie, L., Bruggeman, S. W. M., Solovei, I., Brugman, W., et al. (2010). Molecular maps of the reorganization of genomenuclear lamina interactions during differentiation. Mol. Cell 38, 603-613. doi: 10.1016/j.molcel.2010.03.016

Pickersgill, H., Kalverda, B., de Wit, E., Talhout, W., Fornerod, M., and van Steensel, B. (2006). Characterization of the Drosophila melanogaster genome at the nuclear lamina. Nat. Genet. 38, 1005-1014. doi: 10.1038/ng1852

Pumroy, R. A., and Cingolani, G. (2015). Diversification of importin- $\alpha$ isoforms in cellular trafficking and disease states. Biochem. J. 466, 13-28. doi: 10.1042/ BJ20141186

Raveh, B., Karp, J. M., Sparks, S., Dutta, K., Rout, M. P., Sali, A., et al. (2016). Slide-and-exchange mechanism for rapid and selective transport through the nuclear pore complex. Proc. Natl. Acad. Sci. U.S.A. 113, E2489-E2497. doi: $10.1073 /$ pnas. 1522663113

Roth, C., Lüdke, D., Klenke, M., Quathamer, A., Valerius, O., Braus, G. H., et al. (2017). The truncated NLR protein TIR-NBS13 is a MOS6/IMPORTIN- $\alpha 3$ interaction partner required for plant immunity. Plant J. 92, 808-821. doi: $10.1111 /$ tpj.13717

Saito, K., Yoshikawa, M., Yano, K., Miwa, H., Uchida, H., Asamizu, E., et al. (2007). NUCLEOPORIN85 is required for calcium spiking, fungal and bacterial symbioses, and seed production in Lotus japonicus. Plant Cell 19, 610-624. doi: 10.1105/tpc.106.046938

Sakamoto, Y., Sato, M., Sato, Y., Harada, A., Suzuki, T., Goto, C., et al. (2020). Subnuclear gene positioning through lamina association affects copper tolerance. Nat. Commun. 11:5914. doi: 10.1038/s41467-020-19621-z

Sakamoto, Y., and Takagi, S. (2013). LITTLE NUCLEI 1 and 4 regulate nuclear morphology in Arabidopsis thaliana. Plant Cell Physiol. 54, 622-633. doi: 10. 1093/pcp/pct031

Schmidt, H. B., and Görlich, D. (2016). Transport selectivity of nuclear pores. Trends Biochem. Sci. 41, 46-61. doi: 10.1016/j.tibs.2015.11.001

Schwartz, T. U. (2016). The structure inventory of the nuclear pore complex. J. Mol. Biol. 428, 1986-2000. doi: 10.1016/j.jmb.2016.03.015

Segref, A., Sharma, K., Doye, V., Hellwig, A., Huber, J., Lührmann, R., et al. (1997). Mex67p, a novel factor for nuclear mRNA export, binds to both poly(A)+ RNA and nuclear pores. $E M B O J .16,3256-3271$. doi: 10.1093/emboj/16.11.3256
Smith, S., Galinha, C., Desset, S., Tolmie, F., Evans, D., Tatout, C., et al. (2015). Marker gene tethering by nucleoporins affects gene expression in plants. Nucleus 6, 471-478. doi: 10.1080/19491034.2015.1126028

Snay-Hodge, C. A., Colot, H. V., Goldstein, A. L., and Cole, C. N. (1998). Dbp5p/Rat8p is a yeast nuclear pore-associated DEAD-box protein essential for RNA export. EMBO J. 17, 2663-2676. doi: 10.1093/emboj/17.9.2663

Sørensen, B. B., Ehrnsberger, H. F., Esposito, S., Pfab, A., Bruckmann, A., Hauptmann, J., et al. (2017). The Arabidopsis THO/TREX component TEX1 functionally interacts with MOS11 and modulates mRNA export and alternative splicing events. Plant Mol. Biol. 93, 283-298. doi: 10.1007/s11103-016-0561-9

Stewart, M. (2010). Nuclear export of mRNA. Trends Biochem. Sci. 35, 609-617. doi: 10.1016/j.tibs.2010.07.001

Sträßer, K., Masuda, S., Mason, P., Pfannstiel, J., Oppizzi, M., Rodriguez-Navarro, S., et al. (2002). TREX is a conserved complex coupling transcription with messenger RNA export. Nature 417, 304-308. doi: 10.1038/nature746

Tamura, K., Fukao, Y., Hatsugai, N., Katagiri, F., and Hara-Nishimura, I. (2017). Nup82 functions redundantly with Nup136 in a salicylic acid-dependent defense response of Arabidopsis thaliana. Nucleus 8, 301-311. doi: 10.1080/ 19491034.2017.1279774

Tamura, K., Fukao, Y., Iwamoto, M., Haraguchi, T., and Hara-Nishimura, I. (2010). Identification and characterization of nuclear pore complex components in Arabidopsis thaliana. Plant Cell 22, 4084-4097. doi: 10.1105/tpc.110.079947

Tamura, K., and Hara-Nishimura, I. (2013). The molecular architecture of the plant nuclear pore complex. J. Exp. Bot. 64, 823-832. doi: 10.1093/jxb/ers258

Tang, M., Ning, Y., Shu, X., Dong, B., Zhang, H., Wu, D., et al. (2017). The Nup98 homolog APIP12 targeted by the effector AvrPiz-t is involved in rice basal resistance against Magnaporthe oryzae. Rice 10:5. doi: 10.1186/s12284017-0144-7

Tang, Y., Huang, A., and Gu, Y. (2020). Global profiling of plant nuclear membrane proteome in Arabidopsis. Nat. Plants 6, 838-847. doi: 10.1038/s41477-0200700-9

Tseng, S. S.-I., Weaver, P. L., Liu, Y., Hitomi, M., Tartakoff, A. M., and Chang, T.-H. (1998). Dbp5p, a cytosolic RNA helicase, is required for poly(A)+ RNA export. EMBO J. 17, 2651-2662. doi: 10.1093/emboj/17.9.2651

Uddin, M. N., Akhter, S., Chakraborty, R., Baek, J. H., Cha, J.-Y., Park, S. J., et al. (2017). SDE5, a putative RNA export protein, participates in plant innate immunity through a flagellin-dependent signaling pathway in Arabidopsis. Sci. Rep. 7:9859. doi: 10.1038/s41598-017-07918-x

Van Bortle, K., and Corces, V. G. (2012). Nuclear organization and genome function. Annu. Rev. Cell Dev. Biol. 28, 163-187. doi: 10.1146/annurev-cellbio101011-155824

van Steensel, B., and Belmont, A. S. (2017). Lamina-Associated domains: links with chromosome architecture, heterochromatin, and gene repression. Cell 169, 780-791. doi: 10.1016/j.cell.2017.04.022

Verslues, P. E., Guo, Y., Dong, C.-H., Ma, W., and Zhu, J.-K. (2006). Mutation of SAD2, an importin $\beta$-domain protein in Arabidopsis, alters abscisic acid sensitivity. Plant J. 47, 776-787. doi: 10.1111/j.1365-313X.2006. 02833.x

Wang, B., Duan, C.-G., Wang, X., Hou, Y.-J., Yan, J., Gao, C., et al. (2015). HOS1 regulates argonautel by promoting transcription of the microRNA gene MIR168b in Arabidopsis. Plant J. 81, 861-870. doi: 10.1111/tpj.12772

Wang, H., Dittmer, T. A., and Richards, E. J. (2013). Arabidopsis CROWDED NUCLEI (CRWN) proteins are required for nuclear size control and heterochromatin organization. BMC Plant Biol. 13:200. doi: 10.1186/14712229-13-200

Wang, S., Gu, Y., Zebell, S. G., Anderson, L. K., Wang, W., Mohan, R., et al. (2014). A noncanonical role for the CKI-RB-E2F cell-cycle signaling pathway in plant effector-triggered immunity. Cell Host Microbe 16, 787-794. doi: 10. 1016/j.chom.2014.10.005

Wang, W., Ye, R., Xin, Y., Fang, X., Li, C., Shi, H., et al. (2011). An importin $\beta$ protein negatively regulates MicroRNA activity in Arabidopsis. Plant Cell 23, 3565-3576. doi: 10.1105/tpc.111.091058

Wiermer, M., Cheng, Y. T., Imkampe, J., Li, M., Wang, D., Lipka, V., et al. (2012). Putative members of the Arabidopsis Nup107-160 nuclear pore sub-complex contribute to pathogen defense. Plant J. 70, 796-808. doi: 10.1111/j.1365-313X. 2012.04928.x

Wiermer, M., Germain, H., Cheng, Y. T., García, A. V., Parker, J. E., and Li, X. (2010). Nucleoporin MOS7/Nup88 contributes to plant immunity and nuclear 
accumulation of defense regulators. Nucleus 1, 332-336. doi: 10.4161/nucl.1.4. 12109

Wirthmueller, L., Roth, C., Banfield, M., and Wiermer, M. (2013). Hop-on hopoff: importin- $\alpha$-guided tours to the nucleus in innate immune signaling. Front. Plant Sci. 4:149. doi: 10.3389/fpls.2013.00149

Wirthmueller, L., Roth, C., Fabro, G., Caillaud, M.-C., Rallapalli, G., Asai, S., et al. (2015). Probing formation of cargo/importin- $\alpha$ transport complexes in plant cells using a pathogen effector. Plant J. 81, 40-52. doi: 10.1111/tpj.12691

Wu, S.-J., Wang, L.-C., Yeh, C.-H., Lu, C.-A., and Wu, S.-J. (2010). Isolation and characterization of the Arabidopsis heat-intolerant 2 (hit2) mutant reveal the essential role of the nuclear export receptor EXPORTIN1A (XPO1A) in plant heat tolerance. New Phytol. 186, 833-842. doi: 10.1111/j.1469-8137.2010. 03225.x

Xiao, L., Jiang, S., Huang, P., Chen, F., Wang, X., Cheng, Z., et al. (2020). Two Nucleoporin 98 homologous genes jointly participate in the regulation of starch degradation to repress senescence in Arabidopsis. BMC Plant Biol. 20:292. doi: 10.1186/s12870-020-02494- 1

Xiong, F., Zhang, B.-K., Liu, H.-H., Wei, G., Wu, J.-H., Wu, Y.-N., et al. (2020). Transcriptional regulation of PLETHORA1 in the root meristem through an importin and its two antagonistic cargos. Plant Cell 32, 3812-3824. doi: 10.1105/ tpc. 20.00108

Xu, F., Jia, M., Li, X., Tang, Y., Jiang, K., Bao, J., et al. (2021). Exportin-4 coordinates nuclear shuttling of TOPLESS family transcription corepressors to regulate plant immunity. Plant Cell 33, 697-713. doi: 10.1093/plcell/koaa047

Xu, F., Kapos, P., Cheng, Y. T., Li, M., Zhang, Y., and Li, X. (2014). NLR-associating transcription factor bHLH84 and its paralogs function redundantly in plant immunity. PLoS Pathog. 10:e1004312. doi: 10.1371/journal.ppat.1004312

Xu, S., Zhang, Z., Jing, B., Gannon, P., Ding, J., Xu, F., et al. (2011). Transportin$\mathrm{SR}$ is required for proper splicing of resistance genes and plant immunity. PLoS Genet. 7:e1002159. doi: 10.1371/journal.pgen.1002159

Xu, X., Wan, W., Jiang, G., Xi, Y., Huang, H., Cai, J., et al. (2019). Nucleocytoplasmic Trafficking of the Arabidopsis WD40 repeat protein XIW1 regulates ABI5 stability and abscisic acid responses. Mol. Plant 12, 1598-1611. doi: 10.1016/j.molp.2019.07.001

Xu, X. M., Rose, A., Muthuswamy, S., Jeong, S. Y., Venkatakrishnan, S., Zhao, Q., et al. (2007). NUCLEAR PORE ANCHOR, the Arabidopsis homolog of Tpr/Mlp1/Mlp2/Megator, is involved in mRNA export and SUMO homeostasis and affects diverse aspects of plant development. Plant Cell 19, 1537-1548. doi: 10.1105/tpc.106.049239

Yang, Y., La, H., Tang, K., Miki, D., Yang, L., Wang, B., et al. (2017). SAC3B, a central component of the mRNA export complex TREX-2, is required for prevention of epigenetic gene silencing in Arabidopsis. Nucleic Acids Res. 45, 181-197. doi: 10.1093/nar/gkw850

Yano, R., Oakes, M., Yamaghishi, M., Dodd, J. A., and Nomura, M. (1992). Cloning and characterization of SRP1, a suppressor of temperature-sensitive RNA polymerase I mutations, in Saccharomyces cerevisiae. Mol. Cell. Biol. 12, 5640-5651. doi: 10.1128/MCB.12.12.5640

Yoshida, Y., Sano, R., Wada, T., Takabayashi, J., and Okada, K. (2009). Jasmonic acid control of GLABRA3 links inducible defense and trichome patterning in Arabidopsis. Development 136, 1039-1048. doi: 10.1242/dev.030585
Zhang, A., Wang, S., Kim, J., Yan, J., Yan, X., Pang, Q., et al. (2020). Nuclear pore complex components have temperature-influenced roles in plant growth and immunity. Plant Cell Environ. 43, 1452-1466. doi: 10.1111/pce. 13741

Zhang, B., You, C., Zhang, Y., Zeng, L., Hu, J., Zhao, M., et al. (2020). Linking key steps of microRNA biogenesis by TREX-2 and the nuclear pore complex in Arabidopsis. Nat. Plants 6, 957-969. doi: 10.1038/s41477-020-0726-Z

Zhang, Z., Guo, X., Ge, C., Ma, Z., Jiang, M., Li, T., et al. (2017). KETCH1 imports HYL1 to nucleus for miRNA biogenesis in Arabidopsis. Proc. Natl. Acad. Sci. U.S.A. 114, 4011-4016. doi: 10.1073/pnas.1619755114

Zhao, J., Zhang, W., Zhao, Y., Gong, X., Guo, L., Zhu, G., et al. (2007). SAD2, an importin $\beta$-like protein, is required for UV-B response in Arabidopsis by mediating MYB4 nuclear trafficking. Plant Cell 19, 3805-3818. doi: 10.1105/ tpc.106.048900

Zhao, W., Guan, C., Feng, J., Liang, Y., Zhan, N., Zuo, J., et al. (2016). The Arabidopsis CROWDED NUCLEI genes regulate seed germination by modulating degradation of ABI5 protein. J. Integr. Plant Biol. 58, 669-678. doi: $10.1111 /$ jipb. 12448

Zheng, Y., Zhan, Q., Shi, T., Liu, J., Zhao, K., and Gao, Y. (2020). The nuclear transporter SAD2 plays a role in calcium- and $\mathrm{H} 2 \mathrm{O} 2$ mediated cell death in Arabidopsis. Plant J. 101, 324-333. doi: 10.1111/tpj. 14544

Zhu, G., Chang, Y., Xu, X., Tang, K., Chen, C., Lei, M., et al. (2019). EXPORTIN 1A prevents transgene silencing in Arabidopsis by modulating nucleo-cytoplasmic partitioning of HDA6. J. Integr. Plant Biol. 61, 1243-1254. doi: 10.1111/jipb. 12787

Zhu, Y., Wang, B., Tang, K., Hsu, C.-C., Xie, S., Du, H., et al. (2017). An Arabidopsis nucleoporin NUP85 modulates plant responses to ABA and salt stress. PLoS Genet. 13:e1007124. doi: 10.1371/journal.pgen.1007124

Zhu, Z., Xu, F., Zhang, Y., Cheng, Y. T., Wiermer, M., Li, X., et al. (2010). Arabidopsis resistance protein SNC1 activates immune responses through association with a transcriptional corepressor. Proc. Natl. Acad. Sci. U.S.A. 107, 13960-13965. doi: 10.1073/pnas.1002828107

Conflict of Interest: The authors declare that the research was conducted in the absence of any commercial or financial relationships that could be construed as a potential conflict of interest.

Publisher's Note: All claims expressed in this article are solely those of the authors and do not necessarily represent those of their affiliated organizations, or those of the publisher, the editors and the reviewers. Any product that may be evaluated in this article, or claim that may be made by its manufacturer, is not guaranteed or endorsed by the publisher.

Copyright (C) 2021 Lüdke, Rohmann and Wiermer. This is an open-access article distributed under the terms of the Creative Commons Attribution License (CC BY). The use, distribution or reproduction in other forums is permitted, provided the original author(s) and the copyright owner(s) are credited and that the original publication in this journal is cited, in accordance with accepted academic practice. No use, distribution or reproduction is permitted which does not comply with these terms. 